\title{
The market for conservation and other hostages
}

\author{
Bård Harstad ${ }^{1}$ \\ University of Oslo, Norway \\ Received 9 February 2015; final version received 17 July 2016; accepted 21 July 2016 \\ Available online 2 August 2016
}

\begin{abstract}
A "conservation good" (such as a tropical forest) is owned by a seller who is tempted to consume (or cut), but a buyer benefits more from conservation. The seller prefers to conserve if the buyer is expected to buy, but the buyer is unwilling to pay as long as the seller conserves. This contradiction implies that the market for conservation cannot be efficient and conservation is likely to fail. A leasing market is inefficient for similar reasons and dominates the sales market if and only if the consumption value and the buyer's protection cost are large. The theory thus explains why optimal conservation often fails and why conservation abroad is leased, while domestic conservation is bought.

(c) 2016 The Author. Published by Elsevier Inc. This is an open access article under the CC BY-NC-ND license (http://creativecommons.org/licenses/by-nc-nd/4.0/).

JEL classification: D78; D62; H87; Q30; Q23

Keywords: Conservation; Dynamic games; Sales v rental markets; Deforestation; Market failure; Time inconsistency

\footnotetext{
E-mail address: bardh@econ.uio.no.

1 This revision has benefited from the comments of an Associate Editor and four anonymous referees. I am also grateful to from audiences at the University of Bonn, CESifo, University of Chicago, the 2012 Conflict-and-Cooperation conference at Northwestern University, ETH Zurich, John Hopkins University, LSE, NBER Law \& Economics 2011 Summer Meeting, Northwestern University, the Norwegian School of Economics, the Norwegian University of Life Sciences, the University of Oslo, University of Oxford, Paris School of Economics, The Princeton Political Economy Conference, Resources for the Future, Toulouse School of Economics, the World Bank, WZB Berlin, Yale University; and in particular the comments of Daron Acemoglu, Manuel Amador, Stefan Ambec, Arild Angelsen, Geir Asheim, Jeff Ely, Atle Guttormsen, Johannes Hörner, Philippe Jehiel, Margaret Meyer, Benny Moldovanu, Frikk Nesje, Martin Osborne, Chris Snyder, Bruno Strulovici, and Andreas Westermark. Kevin Bryan and Anders Hovdenes have been excellent research assistants and Judith Levi provided editorial assistance. The author received funding from the European Research Council under the EU's 7th Framework Programme, ERC GA n 283236, and the EU's Horizon 2020 research and innovation programme, GA ${ }^{\circ} 683031$.
} 


\section{Introduction}

This paper introduces the notion of "conservation goods" and shows how they differ fundamentally from traditional goods in dynamic settings. Traditional goods are purchased by buyers who intend to consume the good: trade is typically predicted to take place immediately if the buyer's consumption value is larger than the seller's. For conservation goods, in contrast, the buyer is satisfied with the status quo: he does not desire to consume the good, but buys only if he fears that the seller will consume. This feature implies that the market for conservation goods tends to be inefficient. I find that the inefficiencies arise in rental markets as well as in sales markets; a comparison between the two generates new insight for when leasing is preferred to sales.

Tropical forests are conservation goods-in the framework of this paper. On the one hand, the South benefits from selling the timber and clearing the land for agriculture or oil extraction. On the other hand, the North prefers to have conservation in the South because tropical forests are among the most biodiverse areas in the world, they are inhabited by indigenous people, and deforestation contributes to 10-20 percent of the world's carbon dioxide emissions, which cause global warming. ${ }^{2}$ Negative externalities from forest loss and degradation cost between $\$ 2$ trillion and $\$ 4.5$ trillion a year according to The Economist. ${ }^{3}$ However, deforestation could be halved at a cost of \$21-35 billion per year (Edenhofer et al., 2014), or reduced by 20-50 percent at a price of \$5-10/tCO2.3 (Stern, 2008; Busch et al., 2012). Given these estimates, it is puzzling why the North is not buying conservation on a large scale-despite having established the UN program REDD (Reducing Emissions from Deforestation and Forest Degradation), and that it continues to allow about 13 million hectares of forest to disappear every year (FAO, 2010).

Even unextracted coal and oil can be conservation goods when there are environmental benefits from keeping the resources in the ground. In fact, I have elsewhere argued that a climate coalition may prefer to "buy coal" to ensure it is left in the ground (Harstad, 2012). Framstad and Harstad (2016) study the optimal contracts and Harstad and Mideksa (2016) show how they depend on the political regime. The present paper can explain why we have not seen such a solution in reality. ${ }^{4}$

There are many other examples of "payments for environmental/ecosystem services" (PES; Engel et al., 2008). In the United States, The Nature Conservancy frequently uses land acquisition as a tool of its conservation effort. But the outcome is often inefficient. On the Solomon Islands, for example, villagers had agreed with the Earth Island Institute to protect bottlenose dolphins in return for \$2.4 million SBD (Solomon Island Dollars). When the pay was delayed, the villagers retaliated by slaughtering as many as 900 dolphins. ${ }^{5}$ The seller's desire to conserve only because she hopes to receive payments in the future makes the good reminiscent to a "hostage." 6

\footnotetext{
2 The estimates have varied within this interval since IPCC (2007, see also 2013).

3 September 23, 2010, where The Economist cites a UN-backed effort, The Economics of Ecosystems and Biodiversity (TEEB).

4 Nevertheless, some proposals in this direction have been made. In 2007, President Rafael Correa of Ecuador launched an initiative to raise $\$ 3,6$ b to protect Yasuni National Park, one of the most biodiverse spots on earth. In 2013 the plan was scrapped and the Park opened to oil drilling, after less than a tenth of the requested amount had been pledged and less than half a percent received (Reuters, Aug. 16, 2013).

5 The Epoch Times, January 24th, 2013. Webpage: http://www.theepochtimes.com/n2/world/solomon-island-villagerskill-900-dolphins-in-retaliation-339833.html. I thank Atle Guttormsen for the story.

6 Theoretically, the conservation good could indeed be real captives or hostages, but there are important differences. First, I assume that the buyer is satisfied with the status quo, i.e., as long as the good is conserved, even though it is
} 
Non-environmental examples of conservation goods are landmark buildings or monuments, historical ruins, or artworks: all these goods may generate a value as long as they are conserved, but the agents who benefit from conservation may be in no hurry to pay.

To formalize the market for conservation, I present a dynamic model with a seller (S), a buyer (B), and a good (e.g., the forest). In each period, B decides whether to buy. As long as B has not yet bought, S has the possibility of consuming-or "cutting." The game is a stopping game which ends after sale or consumption. It is conventionally assumed that no one can commit to future play. The main novelty in the game is that B benefits if $\mathrm{S}$ conserves.

As in most games with an infinite time horizon, there are multiple subgame-perfect equilibria (SPEs), and some of these are efficient. However, if we restrict attention to stationary, Markov-perfect, or renegotiation-proof equilibria, no equilibrium in pure strategies allows for conservation. The buyer cannot buy with probability one, since S would then conserve and there would be no need to buy; a contradiction. The seller cannot cut with probability one, since B would then hurry to buy and S would conserve in the meantime; another contradiction. Instead, the natural equilibria are in mixed strategies. If the strategies were purified, the outcome would be that the forest gradually vanishes.

Since the sales market is inefficient, I also consider a rental market where B can temporarily pay $\mathrm{S}$ for conservation. For the same reasons as before, it cannot be an equilibrium that $\mathrm{B}$ rents with a very high probability, since $S$ would then always conserve, making it unnecessary for B to rent. The inefficiencies are thus similar to the sales market. But the two markets are not identical and, when compared, the model predicts the rental market to be both better and the equilibrium choice if, for example, B faces a high protection cost. This cost is not paid by B when B rents, since $S$ will then have incentives to protect the good herself. ${ }^{7}$ If conservation across borders requires higher protection costs, the result is that domestic conservation will be bought, while conservation abroad will be rented.

The buyer's temptation to hope for the status quo interacts with free-riding incentives when there are multiple buyers. When the model is extended to deal with this situation, I show that when the number of buyers is larger, the probability that at least one buyer pays is reduced. This interaction means that one inefficiency can be reduced by manipulating the other. In particular, with a large number of potential buyers, it may be ex ante optimal to let the buyer privatize the good at the cost of a lower conservation value for everyone, even if this would not be optimal ex post or with only a single buyer.

The next section properly defines conservation goods, discusses their relationship to other goods, and reviews the related literature. Section 3 presents the model and analyzes the sales market, while Section 4 repeats the exercise for rental arrangements and compares the two markets. Although the basic model assumes a single buyer and a seller who has all the bargaining power, Section 5 relaxes both assumptions and discusses possible remedies. Section 6 discusses efficient (non-stationary) SPEs but it also derives the set of renegotiation-proof equilibria and shows that these are similar to the inefficient ones. Section 7 concludes and outlines a way to test the theory's predictions, while Appendix A contains all proofs.

possessed by the seller. Second, I ignore how the incentive to take hostages is affected by commitment (Selten, 1988), reputation, or uncertainty (Lapan and Sandler, 1988).

7 Of course, protection could also be costly to the seller (see footnote 22). The results continue to hold as long as protection is more expensive for the buyer than for the seller. Somanathan et al. (2009) do find that regional forest management in the Himalayas is less expensive than is national management. 


\section{Conservation goods and relatives}

This paper defines conservation goods in the following way: A conservation good is a good that generates nonexcludable benefits as long as it is not consumed. ${ }^{8}$

Conservation goods are special only if a set of conditions are satisfied. First, conservation goods are interesting only when there exists at least one agent (S) who values consumption more than conservation, while at least one other agent (B) prefers conservation. Further, the specificity of conservation goods becomes clear when B's conservation benefit is larger than S's value of consumption. It will also be assumed that the good is initially owned by S. If B owned the good, there would never be any trade under these preferences.

When B's conservation value is higher than S's consumption value, a price exists such that both players benefit from trading at this price relative to the outcome in which $\mathrm{S}$ consumes. Then, $\mathrm{S}$ and $\mathrm{B}$ have the following ranking of alternatives, respectively:

$$
\begin{array}{ccccc}
\text { status quo } & \prec_{S} & \text { consume } & \prec_{S} & \text { payment } \\
\text { consume } & \prec_{B} & \text { payment } & \prec_{B} & \text { status quo }
\end{array}
$$

The preference of the seller, $\mathrm{S}$, is standard, while the fact that the buyer, B, ranks the status quo higher than trade is specific to conservation goods. This ranking comes from the "nonexcludable" term in the definition above, which implies that is not necessary to buy and own the good in order to enjoy the conservation benefit. Thus, B prefers the status quo, in which $\mathrm{S}$ conserves the good, over the outcome where B must pay S for conservation.

The term "as long as" in the above definition points to the dynamics. ${ }^{9}$ In a static game, or in one with a finite number of stages, backward induction proves that $\mathrm{S}$ would consume at the last consumption stage. Anticipating this, B will certainly pay if he has a chance to do so beforehand. When the time horizon is infinite, $\mathrm{S}$ might be willing to conserve if she just expects B to pay later. Thus, anticipating a future agreement, the good may be conserved already today. ${ }^{10}$ The buyer, however, will not pay if the seller conserves in any case. This logic means that reasonable equilibria are in mixed strategies, and that the good must be cut with positive probability. ${ }^{11}$ Consequently, the market for conservation is inefficient even if we abstract from traditional explanations of, for example, deforestation. ${ }^{12}$

\footnotetext{
8 Of course, the good may also generate benefits when consumed. There is no need to impose restrictions on the consumption benefit: it can be private/public, rival/nonrival, or excludable/nonexcludable.

9 Since I focus on the dynamics of conservation goods, the reader may also wonder whether there is any relationship to durable goods. However, durable goods normally provide excludable benefits, and the market for them is typically efficient unless one assumes that the willingness to pay is heterogeneous, nonlinear in the traded quantity, or privately known to the buyer (Coase, 1972; Bulow, 1982). None of these aspects are needed for conservation goods, which instead has the feature that the buyer may prefer the status quo.

10 This benefit contrasts with a frequently made argument in the environmental economics literature, namely, that the expectation of a future environmental policy leads to less conservation today (Kremer and Morcom, 2000) or a worse environment ("the green paradox"; Sinn, 2008 and 2012). The reason for the conflicting results is that in the present paper, the owner is (more than) fully compensated for conservation and thus benefits when the future policy arrives.

11 This mixed-strategy equilibrium differs from classic war-of-attrition models, where every player prefers that the opponent ends the game (Tirole, 1998:311; Muthoo, 1999:241). The literature on inspection games also finds equilibria in mixed strategies, but it relies on asymmetric information (Avenhaus et al., 2002).

12 Among the traditional explanations for deforestation, unclear property rights and difficulties in monitoring and enforcing contracts may be most important, but also corruption, electoral cycles, and multiple users/owners have been pointed to. (See, for example, Alston and Andersson, 2011; Angelsen, 2010, and the references therein.) More recently, Gjertsen et al. (2016) study resource protection and monitoring in a repeated relationship. For empirical studies of the de-
} 
The definition above points out that the distinction between private and public goods is not always sharp. The good may generate rival and excludable benefits when it is consumed, but nonexcludable benefits if it is conserved. This combination is somewhat similar to the trade-offs one faces when public goods are privately provided. The literature has pointed out that private provision of public goods is typically inefficient because of free-riding (Mailath and Postlewaite, 1990), private information (Gradstein, 1992), market power (Chari and Jones, 2000), or the need to provide the good (Ellingsen and Paltseva, 2016). A conservation good, in contrast, does not need to be provided, but_crucially_it can be irreversibly and privately extracted or consumed. $^{13}$

Public goods are a special case of externalities, and the conservation value is a special case of consumption externalities where the negative externality outweighs the consumption benefit for some but not all parties. Consuming the good is also analogous to selling the good to someone interested in consumption rather than conservation. Sales in the presence of externalities were first discussed by Katz and Shapiro (1986) and later analyzed by Jehiel and Moldovanu (1995a and 1995b). These papers present equilibria with inefficiencies and delay, but only under certain assumptions, such as bounded recall, a finite time horizon, and multiple buyers. Without these assumptions, Björnerstedt and Westermark (2009) show there will be no delay when attention is restricted to stationary strategies: trade occurs as soon as the seller is matched with the "right" buyer. This paper does not rest on the three assumptions made by Jehiel and Moldovanu. However, rather than imposing an exogenous matching between the buyer and the seller, as in the literature just mentioned, I follow Diamond (1971) by letting the buyer choose whether to get in touch with the seller. ${ }^{14}$ Assuming trade (and matching) to be voluntary is particularly reasonable when it comes to conservation goods, and it is quite standard in the literature on international environmental agreements to assume that participation; i.e., being present at the bargaining table is both voluntary and necessary for negotiations to proceed. ${ }^{15}$

The analysis uncovers a new drawback of leasing markets: since the market for conservation is inefficient, payoffs may be higher if the parties trade once and for all. This leads to novel results when comparing sales vs. leasing, even though I follow the finance literature when assuming that the seller has a lower cost of protecting or maintaining the good. ${ }^{16}$

terminants of deforestation, see Burgess et al. (2011), Damette and Delacote (2012), or, for an earlier overview, Angelsen and Kaimowitz (1999).

13 Thus, free-riding incentives are not necessary for the inefficiencies in the market for conservation goods: it is enough with a single buyer. Further, there is no private information in the analysis below. Finally, no party can exploit any market power and improve their terms of trade by reducing the traded quantity. This follows because there is a single indivisible good. With many goods and downward-sloping demand curves, Chari and Jones (2000) show that the market for clean air, for example, can be inefficient when the permits are complementary and the parties have market power.

14 This assumption is important: if the buyer and the seller are always and exogenously matched, the proposer will always ensure that the gains from trade are immediately exhausted. Jehiel and Moldovanu (1999) endogenize matching by allowing the seller to reach out to any (set of) buyer(s), and they show that the identity of the final buyer is independent of the initial owner. This is in contrast to my paper, and the explanation is, once again, that in my model the buyer can decide whether to get in touch with the seller. Another paper in this literature is by Jehiel et al. (1996), who let the seller commit to a sales mechanism.

15 See Barrett (2005) for a survey, Dixit and Olson (2000) for public good provision agreements, or Battaglini and Harstad (2016) for a dynamic emission game with coalition formation. In this literature, countries can free-ride simply by not showing up at the bargaining venue. The literature nevertheless predicts full cooperation if there are as few as two parties. The outcome is worse for agreements on conservation, I show, since the buyer(s) prefers the status quo.

16 As stated by Levy and Sarnat (1994:662): "under a full-service lease the lessor provides maintenance; in many cases he may be in a better position to provide such service." The economics literature on sales vs. leasing focuses instead 


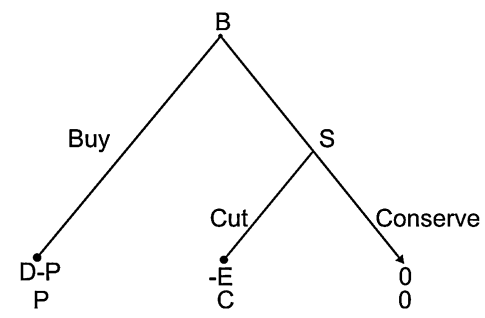

Fig. 1. If B does not buy, S decides whether to cut. The terminal nodes present the buyer's payoff, then the seller's payoff.

\section{The sales market}

\subsection{Stage game}

There is one seller (S; "she"), one buyer (B; "he"), and one indivisible good initially owned by the seller. First, the buyer decides whether to buy the good. If he does, the game ends. If he does not buy, the seller decides whether to consume or conserve the good.

The game is quite standard, and its terminal payoffs are illustrated in Fig. 1. If the buyer purchases the good, he enjoys the direct benefit $D$ although he must pay the price $P$, which in turn equals the seller's payoff. If the buyer does not buy and the seller consumes the good, the seller enjoys the payoff $C>0$. All parameters are common knowledge.

The main novelty in this stage game is that the buyer enjoys some benefit from the existence of the good, whether or not it is purchased. This "existence" value, or perhaps "environmental" benefit, is represented by $E>0$. Payoffs are normalized such that if B does not buy and S does not consume, both payoffs are zero. Thus, the existence value $E$ is experienced as a loss by B if and only if $\mathrm{S}$ consumes. A positive existence value is reasonable for all examples mentioned in the Introduction, but to fix ideas and point to an important example, I will refer to the good as a unit of forest and S's consumption as cutting.

Quite generally, $D$ measures the difference in utility for B between owning and having the good conserved by S. For a traditional good, such as the purchase of a car, $D>0$ and $E=0$. But for a "pure" conservation good, where B enjoys the full value of the good whether B buys or S conserves, then $E>0$ and $D=0$. If there is a cost of maintaining or protecting the forest, then $\mathrm{B}$ may actually prefer that $\mathrm{S}$ owns and conserves it: the protection cost can be measured by $-D$. Thus, $D<0$ is quite reasonable when it comes to conservation goods. Section 4 allows B to pay $\mathrm{S}$ to conserve the good in a rental agreement (then, B saves the protection cost $-D$ ). The model can easily be reformulated to permit a maintenance cost also for the seller (see footnote 22). In this section, parameter $D$ plays a minor role and the reader is free to simplify by assuming that $D=0$.

To make the problem interesting, I will assume:

$$
D<C<D+E \text {. }
$$

Note that the addition of $E$ does not alter the play of the static game: it is a unique best response for $\mathrm{S}$ to consume, given that she reaches her decision node, and (therefore) it is a unique

on the monopolist problem (Bulow, 1982), asymmetric information (Hart and Tirole, 1988; Hendel and Lizzeri, 2002), moral hazard (Henderson and Ioannides, 1983; Smith and Wakeman, 1985), or the combination of these (Johnson and Waldman, 2010). For textbook discussions, see Tirole (1998) or Bolton and Dewatripont (2005). 
best response for B to buy for every $P \in(C, D+E)$. To describe the equilibrium formally, let B's strategy simply be the probability that he buys, $b \in[0,1]$, while S's strategy is the probability that she cuts, $c \in[0,1]$, given that she reaches her decision node.

Proposition 0. Suppose there is only one period.

(i) If $P<D+E, b=1$ and $c=1$.

(ii) If $P=D+E, b \in[0,1]$ and $c=1$.

(iii) In equilibrium, $S$ proposes the price $P=D+E$.

Part (i) shows that the good is conserved with probability one if the price satisfied $P \in(C, D+E)$. The origin of the price $P$ is actually irrelevant for the results of this paper: it can be exogenously given or an endogenous outcome of a bargaining game between $\mathrm{B}$ and $\mathrm{S}$. To be specific, however, I henceforth assume that the exact timing of the stage game is the following. First, the buyer decides whether to contact the seller. In contrast to the traditional literature (reviewed in Section 2), I do not assume that the buyer and the seller necessarily and exogenously match. Instead, I endogenize this matching by letting the buyer make the choice of whether to visit the seller (as in Diamond, 1971, for example). If B does contact S, S proposes a price and $\mathrm{B}$ decides whether to accept. If indifferent, it is conventionally assumed that B accepts S's proposal. If there is no trade, $S$ decides whether to consume. With this, part (i) of the proposition is only for illustration. In equilibrium, $\mathrm{S}$ proposes the price $D+E$ and, anticipating this, $\mathrm{B}$ is indifferent when considering whether to contact $\mathrm{B}$; any $b \in[0,1]$ is therefore an optimal strategy. In particular, there exists a pure-strategy equilibrium in which B contacts $S$ with probability one. The outcome is then first best if $D>0$, but not if $D<0$, since then the first best would require $\mathrm{S}$ to conserve without selling.

\subsection{The dynamic sales game and equilibrium}

Consider the stage game above and suppose that the game ends if the buyer buys or the seller cuts. If no such action is taken, the forest is conserved and the game continues to the next period with the identical stage game.

As before, payoffs are normalized to be zero unless the game stops. Now, the existence value $E$, for example, should be interpreted as the present discounted cost of losing the forest's conservation value forever. The discount factor of player $i \in\{B, S\}$ is $\delta_{i} \in(0,1)$, so if the forest is cut at time $t$, B's present-discounted value of this cost measured at time zero is $\delta_{B}^{t} E$. Parameter $C$ can be interpreted as the market value of the timber when the forest is cut, plus the presentdiscounted value of the agricultural crops that thereafter can be grown on the land. Parameter $D$, or $-D$, may be interpreted as the present discounted cost to B from protecting the forest forever after his purchase. Parameters are assumed to be constant over time for simplicity, and the good is assumed to be indivisible, but both assumptions could be relaxed.

There are many subgame-perfect equilibria in this game, and some of them are efficient; see the discussion in Section 6. The set of stationary and Markov-perfect equilibria (MPEs) is here the same, since the game ends as soon as the stock size changes. There are several reasons for why I emphasize these equilibria below. First, some refinement is necessary to make sensible predictions. Second, MPEs are simple: in the words of Maskin and Tirole (2001:192-193), they "prescribe the simplest form of behavior that is consistent with rationality" while capturing the fact that "bygones are bygones more completely than does the concept of subgame-perfect equilibrium". Third, because the strategies do not depend on the history in arbitrary ways, they 
are robust to any misunderstanding or discoordination between the players regarding which (payoff-irrelevant) history one should condition strategies on. Fourth, and perhaps because of this robustness, subjects in experiments tend to choose Markov-perfect strategies in complex environments (Vespa, 2012; Battaglini et al., forthcoming). Finally, the stationary equilibria are representative for the set of weakly renegotiation-proof equilibria (WRPs). Although WRP may be a more appealing refinement, I postpone that discussion to Section 6 since the set of WRPs is more complicated to derive and explain.

With stationarity, B's strategy is simply his probability of contacting $\mathrm{S}, b \in[0,1]$, and the probability of accepting an offer from $S$ as a function of the proposed price. S's strategy specifies a price offered to $\mathrm{B}$, in case $\mathrm{B}$ contacts $\mathrm{S}$, and the probability of cutting, $c \in[0,1]$, if the good is not sold. One can easily show that B will employ a cutoff strategy by accepting any price lower than some threshold, $P$, and $\mathrm{S}$ will ask for this exact price. Thus, we can summarize the equilibrium strategies as $(b, c, P)$.

If $C>D+E$, no trading price exists that can make trade mutually beneficial. Furthermore, if $C \in\left(\delta_{S}(D+E), D+E\right)$, then $\mathrm{S}$ would prefer to cut, given the chance, even at the highest price which B would be willing to pay, $D+E$. The set of equilibria is then as in the static game: $(b, c, P)=(b, 1, D+E)$, where $b \in[0,1]$. From now on, I thus assume $C<\delta_{S}(D+E)$, which coincides with $C<D+E$ when $\delta_{S} \rightarrow 1$.

\section{Proposition 1.}

(i) There is exactly one equilibrium in pure strategies:

$$
b=0, c=1, P=D+E .
$$

(ii) There are multiple equilibria in mixed strategies. For every price $P \in\left[C / \delta_{S}, D+E\right]$, the strategies $(b, c, P)$ constitute an equilibrium if and only if:

(iii) $\quad b=\frac{C}{P-C}\left(\frac{1-\delta_{S}}{\delta_{S}}\right)$

$$
b \in\left[0, \frac{C}{D+E-C}\left(\frac{1-\delta_{S}}{\delta_{S}}\right)\right]
$$

$$
\begin{aligned}
& \text { and } \quad c=1-\frac{D+E-P}{E-\delta_{B}(P-D)} \quad \text { if } \quad P \in\left[\frac{C}{\delta_{S}}, D+E\right) \text {; } \\
& \text { and } c=1
\end{aligned}
$$$$
\text { if } P=D+E \text {. }
$$

Part (i) describes the unique equilibrium in pure strategies. It is easy to check that this indeed characterizes an equilibrium: When considering S's offer, B is willing to accept $P=D+E$ since $\mathrm{S}$ cuts for sure otherwise. At this $P$, however, it is a best response for $\mathrm{B}$ to never contact $\mathrm{S}$. Since there is no chance for trade, $\mathrm{S}$ cuts. Unfortunately, there is no other equilibrium in pure strategies: If $S$ cuts for sure $(c=1)$, she always requires exactly this price. If, then, B contacts $S$ for sure $(b=1)$, then $\mathrm{S}$ would not cut - a contradiction. Similarly, $c=0$ cannot be an equilibrium since B would then prefer to never buy, and S must prefer to cut.

Part (ii) shows that there are multiple equilibria in mixed strategies. Each equilibrium is characterized by some equilibrium price, and B is indifferent when considering whether to show up while $\mathrm{S}$ is indifferent when considering to cut. Thus, if B contacts $\mathrm{S}$ and he anticipates the equilibrium price $P$, he is indifferent between paying $P$ and continuing the game as if he had never contacted S. S cannot obtain a price higher than the equilibrium $P$, so she proposes exactly this price. This explains why multiple prices are consistent with an equilibrium even if $\mathrm{S}$ can make a take-it-or-leave-it offer when proposing this period's price. (In Section 3.3, S announces the equilibrium price as well as this period's price, leading to a unique equilibrium.)

Each player randomizes such that the opponent is just indifferent and, hence, also willing to randomize. This explains the comparative static. Suppose $P$ increases (i.e., compare an equilibrium with a large price to an equilibrium with a small price). Then, B is less tempted to buy and, 


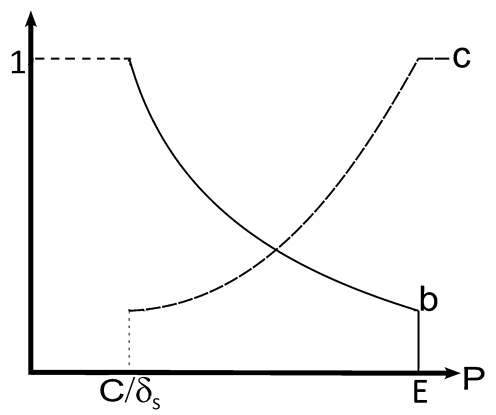

Fig. 2. The buying and cutting probabilities as functions of $P$.

to be willing to randomize, $\mathrm{S}$ must be more likely to cut. At the same time, $\mathrm{S}$ becomes inclined to wait for the high price and thus, B must buy with a smaller probability (as in Fig. 2). For a given $P$, the seller finds cutting more attractive if the market value, $C$, increases or if the future is more discounted, in that $\delta_{S}$ decreases. To ensure that $\mathrm{S}$ is still willing to conserve in these situations, the probability for sale, $b$, must increase. Hence, $\mathrm{B}$ is more likely to buy conservation if the price is small and, perversely, when the market value of cutting is large! Similarly, for a given price, the buyer finds it less attractive to contact $S$ if the value of conservation is low and protection is costly. To ensure that $\mathrm{B}$ is willing to buy, $\mathrm{S}$ must cut with a larger probability in these circumstances.

When we compare to the one-period version of the game, and Proposition 0, two differences are striking. First, if the price were strictly between the two valuations, the good would be conserved with probability one in the static game, but not in the dynamic version. Second, when $\mathrm{S}$ proposes the price, the equilibrium price can be anywhere between the valuations in the dynamic game, but must equal the upper boundary in the static version.

A non-divisible good and mixed strategies are not necessary for these inefficiencies to arise. If there is a mass one of the conservation good, then $b$ can be interpreted as the fraction that is bought every period, while $c$ can be interpreted as the fraction that is cut. ${ }^{17}$

\subsection{Payoffs, prices, and welfare}

At the start of the game, the equilibrium payoff for the buyer, $V_{B}$, is pinned down by the fact that buying is always a best response. Thus, $V_{B}=D-P$. For a traditional good for which $P \leq D$, we have learned that the buyer is willing to purchase with probability one, so that the seller's equilibrium payoff at the start of the game is $V_{S}=P$. The sum of these payoffs is simply $D$, independent of $P$. A more interesting situation arises with conservation goods. In equilibrium, the seller is indifferent between cutting and waiting for her discounted equilibrium payoff, $\delta_{S} V_{S}$. Therefore,

$$
\begin{aligned}
V_{B} & =D-P ; \\
V_{S} & =\frac{C}{\delta_{S}} .
\end{aligned}
$$

\footnotetext{
17 A proof for these claims is available (upon request) and it is based on a number of assumptions. Relaxing these assumptions must be left for future research.
} 
Since trade and transfers are permitted in the model, welfare is simply measured by $V_{B}+$ $V_{S}=C / \delta_{S}-(-D)-P$. When $D<0$, this sum is negative and it quantifies the equilibrium inefficiency since the first-best sum of payoffs is simply zero (i.e., $\mathrm{S}$ conserves forever). Of all equilibria, welfare is certainly larger in the equilibria characterized by a small price. For the lowest possible equilibrium price, B buys with probability one. For the highest possible price, $\mathrm{S}$ cuts with probability one.

How is the equilibrium $P$ selected? The equilibrium price is the anticipated equilibrium, which both $\mathrm{S}$ and $\mathrm{B}$ might take as given. Anticipating this equilibrium, I have let $\mathrm{S}$ propose a price for the current period once B contacts S. Given S's power to propose a price, one may argue that it is reasonable for $\mathrm{S}$ to pick the equilibrium price, as well. For example, once B contacts S, S may make the following statement: "You may think that the equilibrium price is $P$, but let me propose that you purchase at price $P^{\prime}$. Since I am willing to propose $P^{\prime}$ now, it is reasonable that I will propose this $P^{\prime}$ tomorrow as well, and thus $P^{\prime}$ is the price I will consider to be the equilibrium price, from now on." As long as $P^{\prime} \in\left[C / \delta_{S}, D+E\right]$, B will coordinate on this new equilibrium if he believes that $\mathrm{S}$ will do so. Thus, $\mathrm{S}$ does not need to commit when announcing such an equilibrium. After this speech, B will immediately accept, since B is indifferent to trading at $P^{\prime}$ if this is indeed the new equilibrium price. If $\mathrm{S}$ has such power to announce the equilibrium price once $\mathrm{B}$ contacts $\mathrm{S}$, then $\mathrm{S}$ will certainly ask for the highest price in the feasible interval. Thus, $\mathrm{S}$ suggests $P=D+E$ and $\mathrm{B}$ accepts. If the players anticipate all this, then $b$ and $c$ are given by Proposition 1 for $P=D+E$. To summarize:

\section{Corollary 1.}

(i) Total welfare is decreasing in $P$.

(ii) If $S$ announces the equilibrium $P$ when meeting $B$, then:

$$
\begin{aligned}
P & =D+E \Rightarrow \\
b & \leq \frac{C}{D+E-C}\left(\frac{1-\delta_{S}}{\delta_{S}}\right), \\
c & =1, \\
V_{B} & =-E \\
V_{S} & =\frac{C}{\delta_{S}} .
\end{aligned}
$$

If we endogenize the equilibrium price in this way, the probability for conservation is simply $b$, perversely increasing in the value of cutting and decreasing in the value of conservation. Note that, as $\delta_{S} \rightarrow 1, b \rightarrow 0$, and the good is consumed always and immediately. In short, the sales market fails miserably.

\section{The rental market}

\subsection{Stage game}

In a leasing or rental market for conservation, player B pays player $S$ to conserve the good for a given length of time. There are several reasons to analyze this market: (i) the sales market proved to be very inefficient; (ii) existing REDD agreements specify payments conditional on 
annual avoided deforestation, and they are thus more similar to renting than to sales ${ }^{18}$; (iii) it may be very costly for a buyer to protect a forest that is far away; and (iv) a buyer may fear that the seller will attempt to renationalize the forest.

Arguments (iii) and (iv) suggest that buying may be a costly conservation method. The best interpretation of $-D>0$ is that it may represent the present-discounted cost for B when protecting the forest forever against illegal logging or S's attempt to renationalize it. Naturally, this cost is not paid when B rents the forest, since $S$ is then herself interested in protecting the forest so that it can also be rented in the future.

The stage game is otherwise quite similar to the one for the sales market. B first decides whether to contact $\mathrm{S}$. If he does, then $\mathrm{S}$ suggests a rental price, $p$. If $\mathrm{B}$ accepts, $\mathrm{B}$ pays $p$ to $\mathrm{S}$ and the good is conserved until the next period. If no rental contract is signed, $\mathrm{S}$ decides whether to consume. Consumption ends the game and gives the payoff $C$ to $\mathrm{S}$ and $-E$ to $\mathrm{B}$, just as before. The one-period version of the rental game is thus very similar to the one-period version of the sales game, and the two are identical if $D=0$.

\subsection{The dynamic rental game and equilibrium}

As a start, consider only one-period rental contracts (this is relaxed in footnote 21). So, if B rents, $\mathrm{S}$ agrees to conserve and to protect the good for one period but thereafter, the players enter the next period with the identical stage game. Thus, only cutting ends the game.

As before, I let $b$ and $c$ represent the stationary probabilities that $\mathrm{B}$ contacts $\mathrm{S}$ and that $\mathrm{S}$ cuts at her decision node. Thus, B's strategy is simply (i) his probability of contacting $\mathrm{S}$ in any given period, $b \in[0,1]$, and (ii) the threshold $p$ for when he would accept the contract. S' strategy is to offer exactly the price $p$ if $\mathrm{B}$ contacts $\mathrm{S}$ and, at the cutting stage, it specifies the probability of cutting, $c \in[0,1]$. The equilibrium can be summarized by $(b, c, p)$.

If $C>E$, no $p$ can make renting mutually beneficial. If $C \in\left(\delta_{S}\left(1-\delta_{B}\right) /\left(1-\delta_{S}\right), E\right)$, $\mathrm{S}$ prefers to cut even at the highest price that $\mathrm{B}$ would be willing to pay, $E /\left(1-\delta_{B}\right)$, so the equilibrium is simply $(b, c, p)=\left(b, 1, E /\left(1-\delta_{B}\right)\right), b \in[0,1]$. I henceforth assume $C<\delta_{S}\left(1-\delta_{B}\right) /\left(1-\delta_{S}\right)$, which coincides with $C<E$ when discount factors are large.

\section{Proposition 2.}

(i) There is exactly one equilibrium in pure strategies:

$$
b=0, c=1 \text {, and } p /\left(1-\delta_{B}\right)=E \text {. }
$$

(ii) There are multiple equilibria in mixed strategies. For every $p /\left(1-\delta_{B}\right) \in\left[C / \delta_{S}, E\right]$, the strategies $(b, c, p)$ constitute an equilibrium if and only if:
(iii)

$$
b=\frac{C}{p}\left(\frac{1-\delta_{S}}{\delta_{S}}\right)
$$$$
\text { and } \quad c=1-\frac{E\left(1-\delta_{B}\right)-p}{E\left(1-\delta_{B}\right)-\delta_{B} p}
$$$$
\text { if } \frac{p}{1-\delta_{B}} \in\left[\frac{C}{\delta_{S}}, E\right) \text {; }
$$$$
\text { (iv) } b \in\left[0, \frac{C}{\delta_{S} E}\right] \quad \text { and } \quad c=1
$$$$
\text { if } \frac{p}{1-\delta_{B}}=E \text {. }
$$

\footnotetext{
18 Norway's REDD+ agreements with Brazil, Guyana, Indonesia, Tanzania and Mexico can be found online: http:// www.regjeringen.no/en/dep/md/. The United Nations' REDD program is described here: http://www.un-redd.org/.
} 
The equilibrium is analogous to that of the sales market. The comparative static is similar and $b$ and $c$, as functions of $p$, look pretty much like Fig. 2.

Qualitatively, Corollary 1 extends to the rental market. The seller's payoff is simply $C / \delta_{S}$. The price maximizing welfare is the smallest possible price, since, then, $b=1$. However, if $\mathrm{S}$ can announce the equilibrium $p$ when meeting with $\mathrm{B}$, then $p=\left(1-\delta_{B}\right) E$, $b \leq C\left(1-\delta_{S}\right) / \delta_{S}\left(1-\delta_{B}\right) E$, and $c=1$, so cutting takes place relatively fast. ${ }^{19}$

\subsection{Buy or rent conservation?}

In the rental market, the game never ends before $S$ cuts, but, in the meanwhile, the seller is protecting the good and not the buyer. Thus, if $D<0$, renting every period implements the first-best outcome, while a sale implies a loss. Further, a sales market exists only if $E>C+$ $(-D)$, while the rental market exists whenever $E>C$.

To make positive predictions regarding the choice of contracts, consider first the rental market. The buyer anticipates some equilibrium price $p$ and the seller cannot charge a higher rent. However, S may benefit from proposing a sales contract instead. It is reasonable that the two will agree to a sale if and only if there exists some price $P$ such that both $\mathrm{B}$ and $\mathrm{S}$ are better off by trading at $P$ than by continuing to rent.

In the sales market, similarly, B anticipates some equilibrium price $P$. If B contacts $\mathrm{S}, \mathrm{B}$ is unwilling to accept a higher price. Nevertheless, $S$ might proposing a rental agreement instead, if both $\mathrm{B}$ and $\mathrm{S}$ are better off renting at some price $p$ rather than trading at $P .^{20}$

\section{Proposition 3.}

(i) Consider a sales market equilibrium characterized by $P$. There exists a rental contract which both $B$ and $S$ strictly prefer if and only if B's protection cost is high:

$$
(-D)>\frac{\delta_{B} P-C}{1-\delta_{B}} .
$$

(ii) Consider a rental market equilibrium characterized by $p$. There is no sales contract which both $B$ and $S$ weakly prefer if and only if B's protection cost is high:

$$
(-D)>\frac{\delta_{B} p}{1-\delta_{B}}-C \text {. }
$$

(iii) If S can announce the equilibrium price, conservation will be sold if and only if:

$$
(-D)>\delta_{B} E-C \text {. }
$$

\footnotetext{
19 The seller is indifferent when considering protection of the good at the cutting stage, whether or not B has rented the good for this period. Thus, S does not need to precommit and B's payment does not need to be conditioned on actual conservation. However, if S were assumed to protect the good with the same probability whether or not the good would be rented, then there would be no value in a rental arrangement and $\mathrm{B}$ would never rent.

20 The rental contract lasts one period only, and in the following period, either (a) B may consider renting again at some (equilibrium) price, or (b) B and S may revert to the equilibrium in the sales market. Regardless of whether the future is expected to be (a) or (b), the following proposition describes the condition under which a rental contract exists which Pareto-dominates selling at the negotiation stage.
} 


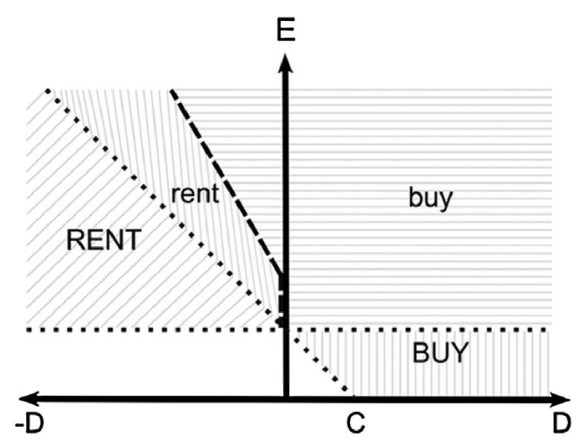

Fig. 3. Renting is better than buying if $-D>0$ is large.

Renting has an advantage if it is costly for the buyer to protect the forest after a purchase, i.e., if $-D>0$ is sufficiently large. The model therefore predicts that conservation of areas far away (where protection would be costly) will be rented, while local conservation, perhaps within the buyer's own country, will be bought.

Interestingly, (i) and (ii) say that a sale is more likely if the equilibrium price is large. At a high price, B contacts $\mathrm{S}$ with a small probability and $\mathrm{S}$ cuts with a high probability. Anticipating the future inefficiencies, $\mathrm{S}$ and $\mathrm{B}$ are better of trading once and for all.

If $S$ can announce the equilibrium price when B contacts her, as in Section 3.3, (5) and (6) are identical and rewritten as (7). Then, when $E$ is large, the price is high, and a sale is preferred: If conservation is sufficiently valuable, conservation is bought rather than rented!

Fig. 3 illustrates the parameter set under which "rent" is preferred by B and S. In the area "rent" (or "buy"), the rental (or sales) market is strictly better: condition (7) is illustrated as the dashed line. In the area "RENT" (or "BUY"), only the rental (sales) market exists. It is also straightforward to allow for a $T$-period leasing agreement, ${ }^{21}$ or for a protection cost for the seller as well as for the buyer. ${ }^{22}$

21 The figure is drawn for the case in which $\delta_{B}=\delta_{S}$. The dashed line is kinked at $E=C / \delta_{S}$, since, for smaller $E$ 's, which have been assumed away, we could have $b=c=1$ in the rental market, and a sales contract would then be better if and only if $D \geq 0$. Note that as $\delta_{B} \rightarrow 1$, the area where renting is preferable converges to the area "RENT," where the sales market is nonexistent: as each period becomes very short, the cost of risking cutting in each of these periods becomes arbitrarily large. This suggests that one-period contracts are unreasonable when $\delta_{B} \rightarrow 1$. With a $T$-period leasing arrangement, (7) will be replaced by (as I show in an earlier version of this paper):

$$
(-D)>\delta_{B}^{T}\left(E-C / \delta_{B}\right)
$$

22 In fact, we can allow for protection costs for the seller without modifying the analysis at all, since $C$ can be interpreted as the value of cutting plus the seller's saved protection cost, if just $D$ is interpreted as the difference in protection costs. To see this, let $G_{B}$ and $G_{S}$ be the present discounted protection costs for B and S, while $\underline{C}$ is the seller's consumption value. With status-quo payoffs normalized to zero, $\mathrm{S}$ gains $\underline{C}+G_{S}$ if she cuts. All equations for the sales market stay unchanged with the interpretations:

$$
C \equiv \underline{C}+G_{S}, D \equiv G_{S}-G_{B}, \text { and } P \equiv \underline{P}+G_{S},
$$

where $\underline{P}$ is the sales price. Note that $D<C$ follows when $\underline{C}>0$ and $G_{B}>0$, and $D<0$ if $G_{S}<G_{B}$. The rental market is also unchanged. An earlier version of this paper discusses all this in detail. 


\section{Multiple buyers, bargaining power, and remedies}

This section extends the analysis by allowing for multiple buyers and an arbitrary allocation of bargaining power when negotiating the price. ${ }^{23}$ Allowing for multiple sellers would not necessarily change the analysis. ${ }^{24}$

Consider first the sales market. There are $n>1$ identical buyers and at the beginning of each period, the buyers simultaneously decide whether to contact the seller. If more than one buyer decides to contact the seller, then each of these buyers is equally likely to be the single buyer who is matched with the seller. The single buyer who trades with the seller pays the cost $P-D$, while every buyer avoids the loss $E$. If no buyer contacts the seller, then $\mathrm{S}$ decides whether or not to cut.

When a buyer is matched with the seller, the two negotiate the price. Let now $\alpha \in(0,1)$ measure the share of the bargaining surplus that goes to the seller. It is straightforward to provide a noncooperative bargaining game generating this outcome: For example, consider a finite alternating-offer bargaining game in which the seller makes the last offer with probability $\alpha$. If discounting is negligible between the offers, then the two players will already agree after the first offer at some price $P \in(C, D+E)$, and $S$ indeed receives the share $\alpha$ of the bargaining surplus. $^{25}$

With these modifications of the model, the equilibrium sales price becomes unique. Furthermore, the price becomes a sensible function of the other parameters in the model: the price will naturally increase in $C$ and in the seller's bargaining power $\alpha$. Interestingly, the price will also increase in the number of buyers. Each buyer is, as before, indifferent between contacting $\mathrm{S}$ and not. When a buyer is matched with $\mathrm{S}$, he is negatively surprised by the fact that no other buyer is matched with $\mathrm{S}$ instead. This loss, which is larger if $n$ is large, adds to the buyer's willingness to pay for ending the game. This willingness to pay is exploited by the seller, who can then ask for a higher price.

To keep the seller indifferent, the probability that some buyer contacts $\mathrm{S}, b$, must be given by the same function as before: $b=C\left(1-\delta_{S}\right) / \delta_{S}(P-C)$. After all, when considering whether to cut, $\mathrm{S}$ is only comparing the value of cutting to the probability that a buyer will show up, regardless of the number of buyers. This implies that when $n$ grows and $P$ increases, $b$ must fall.

23 These two extensions are combined because they complement each other. If the $n>1$ buyers had no bargaining power, one could show that only one buyer could be active in equilibrium. With a single buyer with positive bargaining power, the equilibrium price would collapse to $C / \delta_{S}$, unless the model were extended also in other reasonable directions. 24 There are several ways of introducing multiple sellers. In line with the analysis above, one may assume that a buyer's loss when multiple forests are cut is linearly separable. Thus, if a buyer purchases every forest in the set $M_{B}$ while every forest in the set $M_{C}$ is cut, then the buyer's payoff would be:

$$
\sum_{j \in M_{B}}\left(D_{j}-P_{j}\right)-\sum_{j \in M_{C}} E_{j}
$$

In this situation, whether one forest is purchased, conserved, or cut does not influence any player's payoff when he is considering risking the purchase, conservation, or cutting of another forest. It follows that the game between one seller and the buyer(s) is strategically independent of the outcome or the play with another seller, and each of the games (one for each seller) can be analyzed in isolation, exactly as is done here. However, if the value of cutting depends on how much other sellers cut, the optimal contract becomes more complicated (Framstad and Harstad, 2016) and may depend on the political regime (Harstad and Mideksa, 2016).

25 Alternatively, and in an infinite bargaining game, the bargaining power index can be derived from the differences in $\delta_{S}$ and $\delta_{B}$ (see Muthoo, 1999:52, drawing on Binmore, 1987). 
Thus, with a larger number of buyers, each will contact $S$ with a probability that is reduced so much that even the total probability that one of the $n$ buyers will contact $\mathrm{S}$ is decreasing in $n .{ }^{26}$

Proposition 4. Consider the sales or rental market with $n>1$ and $\alpha \in(0,1)$. There is a unique symmetric equilibrium. In this equilibrium, $b \in(0,1)$ and $c \in(0,1]$. The equilibrium price increases in $C, \alpha$, and $n$, but decreases in $\delta_{S}$ and, in the sales market, also in $D$.

Proposition 4 states (and Appendix A proves) that the same result holds in the rental market, except that $D$ will then play no role. This implies, in turn, that the essence of Proposition 3 continues to hold: when comparing the two markets, there exists a threshold for $D$ such that when a buyer is matched with the seller, the two will benefit from a sale rather than a one-period rental agreement if and only if $(-D)$ is above a certain threshold. ${ }^{27}$

As noted already in Section 3.3, efficiency is larger if the price for conservation is low. The reason is that the seller's payoff is invariant in the price, because a buyer is less likely to contact $\mathrm{S}$ when the price is high, while a low price is beneficial to the buyers. With multiple buyers, the buyers' payoff declines in the price both because the buyer who is matched with the seller then pays more, but also because the larger $P$ reduces $b$, and thus the likelihood that one of the other buyers will pick up the bill. Since $P$ increases in the seller's bargaining-power index $\alpha$, it follows that the outcome would be more efficient if the buyer(s) had more bargaining power. Buyers may be able to raise their bargaining powers by investing in a reputation for being tough negotiators. Although the cost of such an investment would have to be taken into account in a careful analysis, the results above indicate that such an investment may be good for the buyers as well as for efficiency.

Another channel of increasing efficiency, and the buyers' payoffs, is to raise the direct value $D$. In reality, increasing the private value $D$ is a policy option but it may come at some cost. For example, allowing an investor from the rich world to set up fences to reduce the protection cost, or permitting ecotourism in tropical forests to raise the direct private value, comes at the risk of reducing the conservation value for everyone. If we let this aggregate harm be an increasing and convex function of $D$, defined as $H(D)$, then the first-best solution for $D$ is given by $D_{F B} \equiv \arg \max _{D} D-H(D)=H^{\prime-1}(1)$. Thus, once a buyer is matched with the seller, it is not socially optimal to let $D$ increase beyond $D_{F B}$.

Before a buyer has contacted the seller, however, the optimal $D$ is larger. A larger $D$ not only increases the direct benefit of purchasing the good, but also reduces the price $P$ and increases $b$ and $b_{i}$, the probability that a buyer acts. For both reasons, it is ex ante optimal to allow for larger investments in the private value than in the ex post first-best outcome. ${ }^{28}$

26 There is an analogy to the "Kitty Genovese" game (Osborne, 2003, Ch. 4.8), where the likelihood that someone calls the police is decreasing in the number of observers to a crime. In that game, however, there is no player similar to the seller in my game, and thus nothing reflects the increased cutting.

27 The condition can be written as

$$
(-D)>\delta_{B} \frac{C\left(\frac{1-\delta_{S}}{\delta_{S}}\right) / n+(1-b) c E}{1-\delta_{B}+(1-b) c \delta_{B}}-C,
$$

where $b$ and $c$ are the equilibrium strategies in the rental market (an explicit solution for the $D$-threshold cannot be derived, unfortunately). In contrast to the case with a single buyer, the threshold for $D$ does not need to be negative since a rental agreement allows the buyer to hope that someone else will pay in the next period.

28 The proposition holds in the sales market as well as in the rental market. In the rental market, however, the parameter $D$ is above assumed to be irrelevant, so Proposition 5(ii) would hold only weakly. However, if some private value 
Proposition 5. Both $\sum_{i} V_{i}$ and $V_{S}+\sum_{i} V_{i}$ increase if:

(i) $S$ 's bargaining power $\alpha \in(0,1)$ decreases, or

(ii) the private value $D$ increases beyond the first-best level $D_{F B}=H^{\prime-1}$ (1).

Other policies have ambiguous effects on payoffs and efficiency. For example, suppose that the buyers regulated demand or boycotted the harvest. The consequence may be a lower value of cutting, $C$. This policy clearly reduces S's payoff, but it can also reduce the buyers' payoff. The reason is that when $S$ is less tempted to cut, every buyer concludes that $S$ is willing to conserve even if the probability for sale is reduced. In equilibrium, every $b_{j}$ falls if $C$ decreases, and this fall is utility-reducing for a buyer $i$ who had hoped that the other buyers would pay for conservation. This utility loss may outweigh the benefit that a smaller $C$ reduces the equilibrium price. In short, a boycott can be harmful for everyone.

\section{Robustness, refinements, and renegotiation}

This section returns to the basic game of Section 3 to discuss in depth the fundamental inefficiency in the sales market for conservation and how it depends on the equilibrium concept. After all, there are many subgame-perfect equilibria in this game. Some of them are in pure strategies and some are efficient in that they always lead to conservation.

Example. Suppose $D+E>C / \delta_{S}$. We can always find an integer $\Delta>1$ such that:

$$
\delta_{S}^{\Delta}(D+E) \leq C<\delta_{S}^{\Delta-1}(D+E) .
$$

The first inequality means that $\mathrm{S}$ prefers cutting today to selling at price $P=D+E$ in $\Delta$ periods, while the second inequality means that $\mathrm{S}$ prefers selling at price $P=D+E$ in $\Delta-1$ periods to cutting. The following is thus a subgame-perfect equilibrium in pure strategies: $b_{t}=c_{t}=1$ when $t \in\{1,1+\Delta, 1+2 \Delta, .\},. b_{t}=c_{t}=0$ otherwise, the proposed price is $P_{t}=D+E$ when $t \in\{1,1+\Delta, 1+2 \Delta, .$.$\} , and P_{t}=\delta_{B}^{t}(D+E)$ when there are $t$ periods left to one of the next trading time in $\{1,1+\Delta, 1+2 \Delta, .$.$\} . The outcome is that B buys immediately at price D+E$, since $S$ will otherwise cut immediately. If $S$ deviates by not cutting, B does not need to buy in the following period since it is then in the interest of $S$ to wait for trade in $\Delta-1$ periods.

Unfortunately, the strategies in the Example are neither stationary nor Markov-perfect. Markov-perfect equilibria require that strategies be contingent only on "payoff-relevant" partitions of histories (Maskin and Tirole, 2001). Here, the only payoff-relevant aspect to any history is whether or not the game has terminated. ${ }^{29}$

The equilibrium in the Example is not renegotiation proof, either. At the interim stage in period 1 (i.e., when $\mathrm{S}$ is ready to cut because $\mathrm{B}$ did not buy), both players prefer to renegotiate or redefine the time (to period 2, for example). If both players can strictly benefit by simply

(from ecotourism, for example) could be enjoyed by the buyer also in the rental market, then one could argue that Proposition 5(ii) would hold in a strict sense, also for the rental market.

29 The time itself is not payoff-relevant: if one player's strategy is not contingent on time, then the other player cannot benefit from such contingency either. It follows that Markov-perfect equilibria must be in stationary strategies. (I here follow the reasoning of Maskin and Tirole, 2001:202-203, but there exist other interpretations of "Markov-perfect equilibria" which permit non-stationarity; see Duffie et al., 1994.) 
coordinating on another pair of equilibrium strategies, then the initial equilibrium is clearly vulnerable. The rest of this section derives the set of weakly renegotiation-proof equilibria (WRPs), and shows that they are similar to the equilibria described in Proposition 1, before alternative refinements are discussed.

The history of the game is the sequence of actions so far taken. ${ }^{30}$ A strategy for a player is a rule which specifies a randomization over a set of possible moves after every history. A pair of strategies constitutes a Nash equilibrium if each player's strategy is a best response to the other player's strategy, and a subgame-perfect equilibrium if the strategies constitute a Nash equilibrium in every subgame. If two subgames are identical, then the next player to move and the set of possible moves are the same in the two subgames. The following definition is borrowed from Mailath and Samuelson's (2006:134) textbook on repeated games, who draw on Farrell and Maskin (1989).

Definition. An SPE is weakly renegotiation proof $(W R P)$ if the continuation payoffs for any pair of identical subgames are not strictly ranked.

Thus, there is no history after which both players would strictly benefit from following the strategies specified for another identical subgame. Let $S^{W R P}$ denote the set of WRPs.

If we start a new period with history $h$, then B's strategy specifies $b(h)$, the probability that B contacts $\mathrm{S}$ as a function of $h$. Let $P(h)$ be the price $\mathrm{S}$ will propose if B contacts $\mathrm{S}$ after history $h$. Note that $\mathrm{S}$ will not randomize over several $P(h)$ 's: since it is assumed that B accepts S's offer whenever B is indifferent, $\mathrm{S}$ will ask for the highest price acceptable to B. For histories right before the cutting stage, let $h_{c}^{0}(h)$ represent the history when $h$ is followed by B not contacting S, and $h_{c}^{1}(h)$ the history when, after $h, \mathrm{~B}$ contacts S, S proposes $P(h)$, and B declines. Similarly, let the next-period history $h_{+}^{l}(h), l \in\{0,1\}$, be the history where $h_{c}^{l}(h)$ is followed by $\mathrm{S}$ not cutting.

I will refer to as $H_{1}$ the set of possible histories which include at least one period and the buyer is about to decide whether to contact $\mathrm{S}$ (i.e., the game has not yet ended). Similarly, I will refer to $S_{1}^{W R P}$ as the set of equilibria in $S^{W R P}$ which are such that the game does not end in period one with probability one, and which are truncated in that the first period is omitted. I let $(b, c, P) \in S_{1}^{W R P}$ mean that at least one element in $S_{1}^{W R P}$ specifies the strategies $b(h), c(h)$, and $P(h)^{31}$

Proposition 6. The following are equivalent:

(i) $(b, c, P) \in S_{1}^{W R P}$.

(ii) For every history $h \in H_{1}$,

$$
\begin{aligned}
& P(h) \in\left[C / \delta_{S}, D+E\right], \\
& b(h)=\frac{C}{P(h)-C}\left(\frac{1-\delta_{S}}{\delta_{S}}\right) \in(0,1], \text { and }
\end{aligned}
$$

\footnotetext{
30 Although each decision maker is free to randomize over the two actions, the history does not include past randomization probabilities when there is no public randomization device.

31 Of course, an element in $S^{W R P}$ also specifies how B should react after any history which ends with an offer from S. It is not necessary to describe this part of B's strategy here, but note that for $P(h)$ to be part of an SPE, $P(h)$ must be the largest price which B is willing to accept. Furthermore, the following proposition holds even if I have not specified S's probability of cutting after a history where an offer $P \neq P(h)$ has been rejected by B.
} 


$$
\begin{aligned}
& c\left(h_{c}^{l}(h)\right)=1-\frac{D+E-P(h)}{E-\delta_{B}\left(P\left(h_{+}^{l}(h)\right)-D\right)} \in[0,1] \text { if } P(h)>C / \delta_{S} \text { and } l=0 \\
& c\left(h_{c}^{l}(h)\right) \geq 1-\frac{D+E-P(h)}{E-\delta_{B}\left(P\left(h_{+}^{l}(h)\right)-D\right)} \text { if } P(h)=C / \delta_{S} \text { or } l=1 .
\end{aligned}
$$

(iii) After every history $h \in H_{1}, B$ 's and S's continuation values are:

$$
V_{B}(h)=D-P(h) \text { and } V_{S}(h)=C / \delta_{S} .
$$

Note that there is no equilibrium in pure strategies. ${ }^{32}$ The fact that (i) implies (ii) means that if one restricts attention to WRPs, then, after at most one period, B and S must randomize in a similar way to what we have described in Proposition 1 . In fact, $b$ is the same function of $P$ as before, and, if $P\left(h_{+}^{l}(h)\right)=P(h)$, so is $c$. The main difference is that when we do not require the strategies to be stationary or Markov, then the price can change from period to period, and it can also depend on history (in arbitrary ways). The price difference over time can be large, but it is limited by the requirement that the right-hand side of (10) falls in [0,1]. If the equilibrium price in the next period depends on whether or not B contacts $\mathrm{S}$ (but declines S's offer), then $P\left(h_{+}^{0}(h)\right) \neq P\left(h_{+}^{1}(h)\right)$, and also the cutting probabilities $c\left(h_{c}^{0}(h)\right)$ and $c\left(h_{c}^{1}(h)\right)$ must differ accordingly in order to keep $B$ indifferent both when considering to contact $S$ and when considering to accept $S$ 's offer. ${ }^{33}$

Part (iii) of the proposition states that the continuation values take the same form as before. Since (i)-(iii) are equivalent, the proposition also states that in any equilibrium in which B is always willing to buy and $S$ is indifferent when considering to cut, i.e., when (iii) holds, the equilibrium must be weakly renegotiation proof and be characterized by (8)-(11).

The above definition of WRP comes from Farrell and Maskin (1989) and it is commonly used in the literature. The same refinement was independently suggested by Bernheim and Ray (1989), who referred to it as "internal consistency." These refinements are relatively weak, and one might argue that an equilibrium should be considered renegotiation-proof only if it is not dominated by other (renegotiation-proof) equilibria. With this reasoning, Farrell and Maskin

32 As in Proposition 1, there are equilibria in which $P(h)=D+E$, but this requires a unique $b(h) \in(0,1)$ and not as well any other smaller $b$ (including 0 , as in Proposition 1). For smaller $b$ 's, S would have preferred to cut in the previous period, so the game would have ended already. At the opposite extreme, there is an equilibrium in which for every $h \in H_{1}$, we have $P(h)=C / \delta_{S}, b(h)=1$, and $c\left(h_{c}^{0}(h)\right)=1$, but then $c\left(h_{c}^{1}(h)\right) \in(0,1)$, so this equilibrium is not in pure strategies.

33 If the right-hand side of (10) were larger than 1 for $l=0$, B would not buy and $\mathrm{S}$ would have cut in the previous period; if $l=1$, B would not accept $P(h)$ so $\mathrm{S}$ would had to lower the price. If the right-hand side were smaller than zero for $l=0$, B would strictly prefer to contact $\mathrm{S}$ even when $c=0$ and, then, $\mathrm{S}$ could ask for a higher price.

In the special case in which $P(h)=C / \delta_{S}$, then equation (11) only states a lower boundary on $c\left(h_{c}^{0}(h)\right)$. If the inequality is strict, B strictly prefers to buy, but because $P(h)=C / \delta_{S}$, we continue to have $b(h)=1, V_{S}(h)=C / \delta_{S}$, and $\mathrm{S}$ indifferent when considering to cut in the period before.

We cannot prove that (11) binds for $l=1$. A first guess may be that if the inequality is strict, $\mathrm{S}$ could ask for a higher price, since B strictly prefers to buy at price $P(h)$ after contacting B. However, asking for a higher price leads to a different history than $h_{c}^{1}(h)$, and after that history B might no longer prefer to pay. (For example, asking for a higher price could trigger a move to an equilibrium with a smaller price, if that price is rejected by $\mathrm{B}$.)

Finally, note that it is implicitly assumed that $c \in[0,1]$. This restriction can be combined with (11) by writing:

$$
c\left(h_{c}^{l}(h)\right) \in\left[\max \left\{0,1-\frac{D+E-P(h)}{E-\delta_{B}\left(P\left(h_{+}^{l}(h)\right)-D\right)}\right\}, 1\right] \text { if } P(h)=C / \delta_{S} \text { or } l=0 .
$$


define that $s \in S^{W R P}$ is strongly renegotiation proof (SRP) if there is no subgame in which the continuation payoff profile is strictly Pareto-dominated by the continuation payoff profile of another $s^{\prime} \in S^{W R P}$.

By comparing the WRPs described in Proposition 6, none of them appears to be dominated by another: at every cutting stage, S's continuation payoff is $C$, so $\mathrm{S}$ cannot be made strictly better off by moving to another WRP then. Also, at the start of every next period, S's continuation payoff is always $C / \delta_{S}$, so no WRP dominates another. If we seek to rule out the inefficient equilibria in Proposition 6 for not being SRPs, we must do the following:

(1) Construct strategies for the very first period such that $\mathrm{S}$ gets a larger payoff than $C / \delta_{S}$. This is possible, since, in the first period, B may buy with a probability higher than (9) without upsetting S's incentive to cut beforehand (since there is no earlier period). ${ }^{34}$

(2) At the start of any later period, we must allow B and $S$ to renegotiate to (1).

With this, every WRP with $P(h) \geq C / \delta_{S}$ and $b<1$ will be vulnerable to renegotiation.

Unfortunately, (1) and (2) are both unreasonable. The constructed equilibrium (1) is itself vulnerable and it would not be WRP if history did not start with the stage where B can contact S. If the game started with the cutting stage, every WRP would be SRP. ${ }^{35}$

More importantly, (2) requires that B and S can renegotiate at the start of the game as well as at the cutting stage. In other words, we must allow B and $\mathrm{S}$ to renegotiate even before $\mathrm{B}$ decides whether to contact $S$. This does not make much sense: if $B$ can renegotiate with $S$, they may as well discuss the sales price; then, in effect, $B$ is already in contact with $S$. In the game of this paper, it is reasonable to allow for renegotiation only before the cutting stage and, then, every WRP, as described in Proposition 6, is also an SRP, because S's interim payoff cannot be larger than $C$ in an WRP. The proof of Proposition 6 only relies on renegotiation right before the cutting stage, and it holds whether or not the players can renegotiate at any other stage in addition.

\section{Conclusions}

This paper introduces the notion of conservation goods and shows that they are quite different from traditional goods. A buyer is satisfied with the status quo and is willing to buy only if the seller is likely to end conservation; but the seller conserves if she believes the buyer will pay. Reasonable equilibria are in mixed strategies, implying that conservation ends with a positive probability. The model predicts that the buyers are more likely to pay for conservation if the seller's market value of cutting is large, while the seller is less likely to cut if the conservation value is large.

\footnotetext{
34 Proposition 6 does not pin down $b(0)$ for the first period and, when $c\left(h_{c}^{0}(0)\right)$ is given by (10), B is indifferent and willing to buy with a probability that is larger than $C\left(1-\delta_{S}\right) / \delta_{S}(P(0)-C)$. This gives $\mathrm{S}$ a payoff larger than $C / \delta_{S}$. Also $\mathrm{B}$ benefits from this renegotiation if $\mathrm{B}$ and $\mathrm{S}$ renegotiate to an equilibrium where $P(0)$ is strictly smaller than the price in the WRP they are renegotiating from (this is always possible if that price is larger than $C / \delta_{S}$ ). Using the terminology of Bernheim and Ray (1989), this new equilibrium dominates the first and, since the converse is not true, an equilibrium with $P(h) \geq C / \delta_{S}$ will be consistent only if $b=1$ in the very first period.

35 In addition, if we rule out an WRP because it is dominated by another WRP with $b(0)>C\left(1-\delta_{S}\right) / \delta_{S}(P(h)-C)$, then this new WRP is itself not SRP unless $b(0)=1$ (and, if $b(0)=1$, the game would always end in the first period). SRPs are often criticized because the concept rules out SPEs that are defeated through renegotiation only by equilibria that are themselves not viable (Asheim, 1991), and because SRPs may not even exist (Bernheim and Ray, 1989). Abreu et al. (1993) thus develop an alternative approach to renegotiation proofness, but their concept is mainly relevant for symmetric games.
} 
These predictions are empirically testable. Although governments often conserve areas by expropriating property rights, many countries compensate local owners for the losses. The fraction of valuable areas that is conserved, and the speed at which this happens, are typically empirically measurable. When these data are matched with the price the owner receives in compensation, it should be possible to test the model's predictions.

Data on deforestation rates, the allocation of ownerships, and profits from logging is likely to be collected at a larger scale over the next years, since REDD is becoming an important tool for mitigating climate change. While a careful empirical test must await future research, it is interesting to note that the anecdotal evidence on REDD contracts is in line with the theory. First, tropical deforestation is taking place in the South despite the fact that the estimated conservation value is enormous, as discussed in the Introduction. Second, existing REDD contracts are similar to rental agreements, although this is seldom true for domestic conservation, such as national parks. This is exactly as predicted by the theory, if one believes that the protection cost is larger for areas that are further away.

The model above is rather simple, but it has proven flexible enough to be extended in a number of directions. Nonetheless, many questions remain open. To isolate the key feature of conservation goods, I have abstracted from private information, learning, and more complicated utility functions. It may be even more important, in this setting, to study the role of reputation building and alternative bargaining procedures. These aspects should be examined in future research so that we can better understand the important and puzzling nature of conservation markets.

\section{Appendix A. Proofs}

Proof of Proposition 1. At the start of each period, the continuation values for B and S depends on the equilibrium strategies:

$$
\begin{aligned}
& V_{B}(b, c, P)=b(D-P)+(1-b)\left[-c E+(1-c) \delta_{B} V_{B}(b, c, P)\right] ; \\
& V_{S}(b, c, P)=b P+(1-b)\left[c C+(1-c) \delta_{S} V_{S}(b, c, P)\right] .
\end{aligned}
$$

First, note that the equilibrium price must satisfy $P \in\left[C / \delta_{S}, D+E\right]$. A larger price would never be accepted by $\mathrm{B}$, and if the price were smaller, $\mathrm{S}$ would cut with probability one, if given the chance, and B would thus accept any price smaller or equal to $D+E$.

Anticipating an equilibrium price $P \in\left[C / \delta_{S}, D+E\right]$, the game becomes a quitting game and B's decision is whether to stop and get the payoff $D-P$ or to continue. If continuation is a best response, it remains a best response in the subsequent periods and B's payoff becomes:

$$
V_{B}(0, c, P)=-\frac{c E}{1-\delta_{B}(1-c)} \geq V_{B}(1, c, P)=D-P \text { if } c \leq \frac{P-D}{E-\delta_{B}(P-D)}\left(1-\delta_{B}\right) .
$$

It follows that B's best response is

$$
\begin{aligned}
& b=0 \text { if } c<\frac{P-D}{E-\delta_{B}(P-D)}\left(1-\delta_{B}\right), \\
& b \in[0,1] \text { if } c=\frac{P-D}{E-\delta_{B}(P-D)}\left(1-\delta_{B}\right), \\
& b=1 \text { if } c>\frac{P-D}{E-\delta_{B}(P-D)}\left(1-\delta_{B}\right),
\end{aligned}
$$

where $\left(1-\delta_{B}\right)(P-D) /\left[E-\delta_{B}(P-D)\right] \leq 1$ if $P \leq D+E$. 
S's decision at the cutting stage is whether to cut to get $C$ or to continue. If continuation is a best response, it remains a best response in the following periods and S's payoff is:

$$
\delta_{S} V_{S}(b, 0, P)=\frac{\delta_{S} b P}{1-\delta_{S}(1-b)} \geq V_{S}(b, 1, P)=C \text { if } b \geq \frac{C}{P-C} \frac{1-\delta_{S}}{\delta_{S}} .
$$

It follows that $\mathrm{S}$ 's best response is

$$
\begin{aligned}
& c=0 \text { if } b>\frac{C}{P-C} \frac{1-\delta_{S}}{\delta_{S}}, \\
& c \in[0,1] \text { if } b=\frac{C}{P-C} \frac{1-\delta_{S}}{\delta_{S}}, \\
& c=1 \text { if } b<\frac{C}{P-C} \frac{1-\delta_{S}}{\delta_{S}},
\end{aligned}
$$

where $C\left(1-\delta_{S}\right) / \delta_{S}(P-C) \in(0,1)$ if $P>C / \delta_{S}$. Combined with (12), the equilibrium must satisfy:
(a) $b=1$
(b) $b=\frac{C}{P-C}\left(\frac{1-\delta_{S}}{\delta_{S}}\right)$
and $\quad c \in\left[\frac{\left(1-\delta_{B}\right)(P-D)}{E-\delta_{B}(P-D)}, 1\right] \quad$ if $\quad P=\frac{C}{\delta_{S}}$;
(c) $b \in\left[0, \frac{C}{P-C}\left(\frac{1-\delta_{S}}{\delta_{S}}\right)\right]$
and $\quad c=\frac{\left(1-\delta_{B}\right)(P-D)}{E-\delta_{B}(P-D)}$
if $P \in\left(\frac{C}{\delta_{S}}, D+E\right)$;
and $c=1$
if $P=D+E$.

Returning to the equilibrium price, note that in row (a) $c$ must equal the lowest value in the interval: any larger $c$ would mean that B would strictly prefer to buy, and $\mathrm{S}$ could then charge a higher price without fearing that B would reject. In every other equilibrium, as described by (b) and (c), B is indifferent when considering to contact $\mathrm{S}$ and pay the expected price $P$. If $\mathrm{B}$ does contact $\mathrm{S}, \mathrm{S}$ can therefore charge the price $P$, but no higher price.

Proof of Proposition 2. The proof is analogous to the proof of Proposition 1. It is thus omitted here, but available upon request.

Proof of Proposition 3. (i) First, note that if $E<(\leq) C$, there is no rental price that makes both players (strictly) better off than cutting, so the rental market does not exist. Thus, assume $E>C$.

In the sales market, $V_{B}=D-P$. In the rental market, $V_{B}=-p /\left(1-\delta_{B}\right)$, since renting forever in every period is a best response. If $\mathrm{B}$ expects to revert to the sales market in the following period, then $V_{B}=-p+\delta_{B}(D-P)$. In both cases, B is indifferent between renting and buying if:

$$
P=\frac{p}{1-\delta_{B}}+D \Leftrightarrow p=\left(1-\delta_{B}\right)(P-D) .
$$

Once $\mathrm{B}$ has contacted $\mathrm{S}$ to buy, $\mathrm{S}$ expects the payoff $P$. If $\mathrm{S}$ accepts a one-period rental agreement instead, her expected payoff is $p+\delta_{S} V_{S}=p+C$, so $\mathrm{S}$ is indifferent between trading and signing a rental contract if:

$$
P=p+C \Leftrightarrow p=P-C .
$$

(i) We can now conclude that in a sales market with equilibrium price $P$, both the seller and the buyer benefit from instead signing a rental contract if:

$$
P-C \leq p \leq\left(1-\delta_{B}\right)(P-D) .
$$

Such a price $p$ exist if and only if $P-C \leq\left(1-\delta_{B}\right)(P-D) \Rightarrow-D \geq\left(\delta_{B} P-C\right) /\left(1-\delta_{B}\right)$. 
(ii) In a rental market with equilibrium rental price $p$, both the sellers and the buyer benefit from instead trading at price $P$ if:

$$
p+C \leq P \leq \frac{p}{1-\delta_{B}}+D
$$

Such a price $P$ exist if and only if $p+C \leq p /\left(1-\delta_{B}\right)+D \Rightarrow-D \leq \delta_{B} p /\left(1-\delta_{B}\right)-C$.

(iii) This part follows when substituting in for the price $S$ would propose.

Proof of Proposition 4. The sales market: I will first derive $b$ and $c$, given $P$, before determining $P$. The seller's problem at the cutting stage is the same as in the proof of Proposition 1 , and her best response is given by (13), where $b$ is the probability that at least one buyer will show up. With $n$ buyers, $i \in\{1, \ldots, n\}, b$ is also a function of the individual $b_{i}$ 's. In the symmetric equilibrium, the probability that no one contacts $S$ is:

$$
1-b=\left(1-b_{i}\right)^{n} \Rightarrow b_{i}=1-\left(1-\frac{C}{P-C} \frac{1-\delta_{S}}{\delta_{S}}\right)^{1 / n} \text {. }
$$

Let $V_{B}^{\varphi}$ be a buyer's continuation value at the start of a period conditioned on that this particular buyer is about to contact the seller with probability $\varphi \in[0,1]$. Since $V_{B}^{\varphi}=(1-\varphi) V_{B}^{0}+\varphi V_{B}^{1}$, it is clear that, when $b_{i} \neq 0$ :

$$
V_{B}^{0}=V_{B}^{1} \Leftrightarrow V_{B}^{b_{i}}=V_{B}^{0}
$$

This equivalence implies that to determine when a buyer is willing to randomize, we do not need to compare $V_{B}^{0}$ with $V_{B}^{1}$, since it is sufficient to compare $V_{B}^{0}$ with $V_{B}^{b_{i}}$. This is convenient, since it is easier to derive $V_{B}^{b_{i}}$ than to derive $V_{B}^{1}$. To get $V_{B}^{b_{i}}$, the buyer randomizes with the equilibrium probability $b_{i}$, implying that the probability that some buyer contacts $\mathrm{S}$ is simply $b$. Further, when $\mathrm{S}$ is contacted, the probability that $\mathrm{S}$ is contacted by any particular buyer is simply $1 / n$. Thus, a buyer's continuation value is:

$$
\begin{aligned}
V_{B}^{b_{i}} & =b\left(\frac{D-P}{n}\right)+(1-b)\left(-c E+(1-c) \delta_{B} V_{B}^{b_{i}}\right) \Rightarrow \\
V_{B}^{b_{i}} & =\frac{b\left(\frac{D-P}{n}\right)+(1-b)(-c E)}{1-(1-b)(1-c) \delta_{B}} .
\end{aligned}
$$

If instead the buyer is about to contact the seller with probability zero, his continuation value is $V_{B}^{0}=\left(1-b_{i}\right)^{n-1}\left(-c E+(1-c) \delta_{B} V_{B}^{b_{i}}\right)$. From (15), the buyer is willing to randomize if $V_{B}^{b_{i}}=V_{B}^{0}$, and this implies:

$$
b\left(\frac{D-P}{n}\right)+(1-b)\left(-c E+(1-c) \delta_{B} V_{B}^{b_{i}}\right)=\left(1-b_{i}\right)^{n-1}\left(-c E+(1-c) \delta_{B} V_{B}^{b_{i}}\right) .
$$

Note that (17) is, together with (16), pinning down $c$, given $P$ and $b$ (where $b$ follows from $P$, as above). In the following, a buyer's continuation value is simply referred to as $V_{B}$ instead of $V_{B}^{b_{i}}$, since $V_{B}^{b_{i}}=V_{B}^{0}=V_{B}^{1}$.

To determine $P$, note that after $i$ has contacted $\mathrm{S}$, the total bargaining surplus is:

$$
D-C-\left(-c E+(1-c) \delta_{B} V_{B}\right) \text {. }
$$


S's surplus is simply $P-C$, which is a fraction $\alpha \in[0,1]$ of the total surplus if:

$$
P-C=\alpha\left[D-C-\left(-c E+(1-c) \delta_{B} V_{B}\right)\right] .
$$

Solving this equation for $\left(-c E+(1-c) \delta_{B} V_{B}\right)$ and substituting that term into (17), we get:

$$
\begin{gathered}
b\left(\frac{D-P}{n}\right)+(1-b)\left(-c E+(1-c) \delta_{B} V_{B}\right)=\left(1-b_{i}\right)^{n-1}\left(-c E+(1-c) \delta_{B} V_{B}\right) \Rightarrow \\
\Psi=\alpha\left(\frac{P-D}{P-(1-\alpha) C-\alpha D}\right)-\left[n \frac{(1-b)^{1-1 / n}-(1-b)}{b}\right]=0 .
\end{gathered}
$$

Lemma 1 below shows that the bracket is decreasing in $b$, so $\partial \Psi / \partial b>0$. Since $b=\frac{C}{P-C} \frac{1-\delta_{S}}{\delta_{S}}$ and the first term decreases in $P$ and $D$, but increases in $C$ and $\alpha$, we can conclude that $\Psi_{P}<0$, pinning down a unique $P$. Furthermore, $\Psi_{D}<0, \Psi_{C}>0, \Psi_{\alpha}>0$, and $\Psi_{\delta_{S}}<0$. Lemma 2 below shows that the bracket decreases in $n$, so $\Psi_{n}>0$. Since differentiating (18) gives $d P / d k=$ $-\Psi_{k} / \Psi_{P}, k \in\left\{\alpha, C, D, n, \delta_{S}\right\}$, we can conclude that $P$ must increase if $n, \alpha$, or $C$ increases, and if $D$ or $\delta_{S}$ falls.

Lemma 1. $\partial \Psi / \partial b>0$.

Proof. We only need to show that $\left[(1-b)^{\frac{n-1}{n}}-(1-b)\right] / b$ is decreasing in $b$ : This is relatively straightforward to prove and the proof is thus omitted.

Lemma 2. $\Psi_{n}>0$.

Proof. We only need to show that $n\left((1-b)^{1-\frac{1}{n}}-(1-b)\right)$ decreases in $n$ : This is relatively straightforward to prove and the proof is thus omitted.

The rental market: This proof follows the same lines as for the sales market. As before, $\mathrm{S}$ is indifferent between cutting or not only when the probability that someone rents in a period is:

$$
b=\frac{C}{p}\left(\frac{1-\delta_{S}}{\delta_{S}}\right) \Rightarrow b_{i}=1-\left(1-\frac{C}{p}\left(\frac{1-\delta_{S}}{\delta_{S}}\right)\right)^{1 / n},
$$

in the symmetric equilibrium. Buyer $i$ is indifferent between randomizing by contacting $\mathrm{S}$ with probability $b_{i}$ and abstaining from this if:

$$
\begin{aligned}
b\left(\frac{-p}{n}\right)-(1-b) c\left(E+\delta_{B} V_{B}\right) & =-\left(1-b_{j}\right)^{n-1} c\left(E+\delta_{B} V_{B}\right) \Rightarrow \\
b\left(\frac{p}{n}\right) & =\left[\left(1-b_{i}\right)^{n-1}-(1-b)\right] c\left(E+\delta_{B} V_{B}\right) .
\end{aligned}
$$

To determine $p$, note that after $i$ has contacted $\mathrm{S}$, the total bargaining surplus is $c\left(E+\delta_{B} V_{B}\right)$. S's surplus is simply $p$, which is a fraction $\alpha \in[0,1]$ of the total surplus if $p=\alpha c\left(E+\delta_{B} V_{B}\right)$. Substituted into (20), we get:

$$
\Phi=\frac{\alpha}{n}-\frac{1}{b}\left[\left(1-b_{i}\right)^{n-1}-(1-b)\right]=0 .
$$


Since $\partial \Phi / \partial n>0$ and $\partial \Phi / \partial b>0$ for the same reasons as in Lemma 1 and Lemma 2, (21) pins down $b$ as a function that decreases in $n$ and $\alpha$. The price $p$ follows from $p=\frac{C}{b}\left(\frac{1-\delta_{S}}{\delta_{S}}\right)$, so $p$ increases in $n, \alpha$, and $C$, but decreases in $\delta_{S}$.

Proof of Proposition 5. I will prove (ii) first. We have $V_{S}=C / \delta_{S}$, while $V_{i}$ is pinned down by the fact that one best response for buyer $i$ is to contact $S$ with probability one and expect the payoff:

$$
V_{i}=-(P-D) \varsigma
$$

in the sales market, where $\zeta$ is the probability that a buyer is matched with $\mathrm{S}$, conditional on this buyer contacting S. Clearly, $\varsigma \in(1 / n, 1)$, so the sum of the $V_{i}$ 's is larger than $D-P$. A larger $D$ increases $V_{i}$ directly, reduces $P$, and increases $b$, which, in turn, lowers $\varsigma$. Consequently, $\partial \sum_{i} V_{i} / \partial D>1$, while $V_{S}$ is invariant in $D$.

(i) A smaller $\alpha$ reduces $P$, increases $b$, which in turn reduces $\varsigma$, and, hence, $V_{i}$ increases, while $V_{S}$ is unaffected. A similar argument holds for the rental market.

Proof of Proposition 6. Let $H_{c}$ be the set histories such that $\mathrm{S}$ is about to decide whether to cut, and let $U_{B}\left(h_{c}\right)$ and $U_{S}\left(h_{c}\right)$ be the interim continuation values for $\mathrm{B}$ and $\mathrm{S}$ after $h_{c} \in H_{c}$. The main part is to prove that (i) implies (ii). Each lemma below is proven by contradiction.

Lemma 3. For every $h \in H_{1}, P(h) \geq C / \delta_{S}$.

Proof. If $P(h)<C / \delta_{S}, \mathrm{~S}$ would prefer to cut at the previous cutting stage, so the game would already have ended, contradicting $h \in H_{1}$.

Lemma 4. If $s \in S^{W R P}$, then $U_{S}\left(h_{c}\right)=C \forall h_{c} \in H_{c}$.

Proof. Let $h^{+}\left(h_{c}\right) \in H_{1}$ be defined as the history where, after $h_{c}$, S does not cut. Let $h_{c}^{+}\left(h_{c}\right) \in$ $H_{c}$ be the history where $h^{+}\left(h_{c}\right)$ is followed by B not contacting S. Clearly, $U_{S}\left(h_{c}\right) \geq C$, because $\mathrm{S}$ can cut after $h_{c}$. Now, suppose $U_{S}\left(h_{c}^{\prime}\right)>C$ for some $h_{c}^{\prime} \in H_{c}$. Clearly, $U_{S}\left(h_{c}^{\prime}\right)>C$ is possible only if B might buy later. B is willing to by later only if $\mathrm{S}$ might cut after some other history unless B contacts S. Hence, there must be some $h_{c} \in H_{c}$ such that both $U_{S}\left(h_{c}\right)>C$ and $c\left(h_{c}^{+}\left(h_{c}\right)\right)>0 \Rightarrow U_{S}\left(h_{c}^{+}\left(h_{c}\right)\right)=C$. After history $h_{c}^{+}\left(h_{c}\right), \mathrm{S}$ is clearly strictly better off renegotiating to $h_{c}$, and so is also $\mathrm{B}$, it is easy to show: To see that also B strictly prefers to renegotiate to $h_{c}$, note, first, that $\mathrm{S}$ will not cut, so $c\left(h_{c}\right)=0$, if $U_{S}\left(h_{c}\right)>C$. If $b\left(h^{+}\left(h_{c}\right)\right)>0$, B is willing to buy, so, $U_{B}\left(h_{c}^{+}\left(h_{c}\right)\right) \leq D-P\left(h^{+}\left(h_{c}\right)\right)$, which, in turn, is strictly less than $\delta_{B}\left[D-P\left(h^{+}\left(h_{c}\right)\right)\right]=U_{B}\left(h_{c}\right)$, since, from Lemma 3, $P\left(h^{+}\left(h_{c}\right)\right) \geq C / \delta_{S}>D$. If, instead, $b\left(h^{+}\left(h_{c}\right)\right)=0$, B strictly prefers history $h_{c}$ to $h_{c}^{+}\left(h_{c}\right)$ because, when $c\left(h_{c}\right)=b\left(h^{+}\left(h_{c}\right)\right)=0$, $U_{B}\left(h_{c}\right)=\delta_{B} U_{B}\left(h_{c}^{+}\left(h_{c}\right)\right) \Rightarrow U_{B}\left(h_{c}\right)>U_{B}\left(h_{c}^{+}\left(h_{c}\right)\right)$, since B's utility is negative. Intuitively, $\mathrm{B}$ is better off with $c\left(h_{c}\right)=0$, followed by $b\left(h^{+}\left(h_{c}\right), 0\right)=0$ and $c\left(h_{c}^{+}\left(h_{c}\right)\right)>0$, than with $c\left(h_{c}^{+}\left(h_{c}\right)\right)>0$ already now.

Lemma 5. If $s \in S_{1}^{W R P}$, then $b(h)>0 \forall h \in H_{1}$.

Proof. Suppose $b(h)=0$ after some history $h \in H_{1}$. Then, Lemma 4 implies that $V_{S}(h)=$ $U_{S}\left(h_{c}^{0}(h)\right)=C$, which is worth only $\delta_{S} C<C$ in the period before. Thus, $S$ strictly prefers to cut in the period before, contradicting $h \in H_{1}$. 
It is easy to see that if $\mathrm{B}$ contacts $\mathrm{S}$, then the players will trade. B is willing to trade if $D-P \geq$ $U_{B}\left(h_{c}^{1}(h)\right)$, so $\mathrm{S}$ must propose $P(h) \equiv \max P$ s.t. $P \leq D-U_{B}\left(h_{c}^{1}(h)\right)$. Such a $P(h)$ must exist since, by Lemma $4, U_{S}\left(h_{c}^{1}(h)\right)=C$, and since, by Lemma $3, U_{B}\left(h_{c}^{1}(h)\right) \leq D-C / \delta_{S}$, we get $U_{S}\left(h_{c}^{1}(h)\right)+U_{B}\left(h_{c}^{1}(h)\right) \leq D-C\left(1 / \delta_{S}-1\right)<D$, where $D$ is the sum of payoffs after trade.

With this, we know that there must be a possibility for trade after every history in $H_{1}$.

Lemma 6. For every $h \in H_{1}, P(h) \leq D+E$.

Proof. If $P(h)>D+E$, B is better off not buying, contradicting Lemma 5 .

By combining Lemma 3 and Lemma 6, we can restrict attention to equilibria in which $P(h) \in\left[C / \delta_{S}, D+E\right] \forall h \in H_{1}$. It is easy to check that for every such $P(h), \mathrm{B}$ and $\mathrm{S}$ are willing to randomize with $b$ and $c$ if and only if these strategies are as given by Proposition 6. To derive these probabilities, I will in the following let variables with starred superscript refer to the right-hand sides of (8)-(11).

Lemma 7. (a) If $s \in S^{W R P}$, then $b(h) \leq b^{*}(h)$ for every $h \in H_{1}$. (b) In every $\operatorname{SPE}, c\left(h_{c}^{0}(h)\right) \leq$ $c^{*}\left(h_{c}^{0}(h)\right)$ for every $h \in H_{1}$.

Proof. (a) Suppose $s \in S^{W R P}$ and that at some $h \in H_{1}, b(h)>b^{*}(h)$. Then, in the previous period, $U_{S}>C$, contradicting Lemma 4 .

(b) If $c\left(h_{c}^{0}(h)\right)>c^{*}\left(h_{c}^{0}(h)\right)$, B would strictly prefer to contact S: this would violate part (a) if $P(h)>C / \delta_{S} \Rightarrow b^{*}(h)<1$, but, if $P(h)=C / \delta_{S} \Rightarrow b^{*}(h)=1$, it is possible that $c\left(h_{c}^{0}(h)\right)>$ $c^{*}\left(h_{c}^{0}(h)\right)$ although, since $b^{*}(h)=1$, the game would end before the cutting stage.

Lemma 8. (a) For every $h \in H_{1}, b(h) \geq b^{*}(h)$. (b) If $s \in S_{1}^{W R P}$, then $c\left(h_{c}^{l}(h)\right) \geq c^{*}\left(h_{c}^{l}(h)\right)$, $l \in\{0,1\}$.

Proof. (a) Suppose $b(h)<b^{*}(h)$ for some $h \in H_{1}$. Then, in the previous period, S would strictly prefer to cut, and the game would have ended already, contradicting $h \in H_{1}$.

(b) If $c\left(h_{c}^{0}(h)\right)<c^{*}\left(h_{c}^{0}(h)\right)$ for some $h \in H_{1}$, then B would prefer $b(h)=0$, contradicting Lemma 5. If $c\left(h_{c}^{1}(h)\right)<c^{*}\left(h_{c}^{1}(h)\right)$ for some $h \in H$, then B would not be willing to pay $P(h)$ after contacting $\mathrm{S}$, which contradicts that $P(h)$ is an equilibrium price.

With this, we have shown that if $s \in S_{1}^{W R P}$, then (8)-(11) hold for every $h \in H_{1}$. Note that $U_{S}\left(h_{c}\right)=C$ also in the first period, so $\mathrm{S}$ received the same continuation payoff before every cutting stage, so there is no scope for renegotiation then. It is easy to find first-period strategies so that (8)-(11) can be a part of a WRP, simply assume that (8)-(11) hold also in the first period, for example. Thus, (ii) implies (i), as well.

(iii) If $s \in S^{W R P}$, B is willing to buy and $\mathrm{S}$ willing to cut, so their equilibrium payoffs are $D-P(h)$ and $C / \delta_{S}$. To show that the converse is also true, note that whenever $V_{S}(h)=C / \delta_{S}$ for $h \in H_{1}$, we must in the period before have had $U_{S}\left(h_{c}\right)=C$. Since this holds for every $h \in H_{1}$, S cannot strictly benefit from switching to any other history with the identical subgame, so $s \in S^{W R P}$. 
Remark on SRP versus WRP. While Proposition 6 focuses on $S_{1}^{W R P}, S^{W R P}$ follows from combining $S_{1}^{W R P}$ with any of the following first-period strategies (with history "0"). Any price $P(0) \in[C, D+E]$ can be part of $S^{W R P}$, but we must have $c\left(\widehat{h}_{1}(0)\right) \geq c^{*}\left(\widehat{h}_{1}(0)\right)$ for B to be willing to pay $P(0)$. Regarding $b(0)$ and $c\left(\widehat{h}_{0}(0)\right)$, the following four alternatives are all WRPs:

(i) $b(0)=\max \left\{1, b^{*}(0)\right\}$ and $c\left(\widehat{h}_{0}(0)\right)=c^{*}\left(\widehat{h}_{0}(0)\right) \in[0,1]$,

for all $P(0) \in[C, D+E]$,

(ii) $b(0)=0$ and $c\left(\widehat{h}_{0}(0)\right)<c^{*}\left(\widehat{h}_{0}(0)\right) \in[0,1]$, if $P(0) \leq \min _{h \in H} P(h)$,

(iii) $b(0) \in\left[0, b^{*}(0)\right)$ and $c\left(\widehat{h}_{0}(0)\right)=c^{*}\left(\widehat{h}_{0}(0)\right) \in[0,1]$, if $P(0) \leq \min _{h \in H} P(h)$,

(iv) $b(0) \in\left(b^{*}(0), 1\right]$ and $c\left(h_{c}^{0}(0)\right)=c^{*}\left(h_{c}^{0}(0)\right) \in[0,1]$, if $P(0) \geq \max _{h \in H_{1}} P(h)$.

Since (iv) allows $b(0)>b^{*}(0), \mathrm{S}$ can at the very beginning receive a continuation value larger than $C / \delta_{S}$. Thus, any WRP with $P(h)>C / \delta_{S}$ and $b(h)=b^{*}(0)<1$ for some $h \in H_{1}$ can be dominated by some other WRP of type (iv) with a smaller price and $b(0)>b^{*}(0)$. However, if this $b(0)<1$, it is itself not SRP! If $b(0)=1$, the game would have ended immediately, so the new equilibrium is not in $S_{1}^{W R P}$. Furthermore, using (iv) to dominate the other WRPs require $\mathrm{B}$ and $\mathrm{S}$ to renegotiate at the start of a period, while the proof of Proposition 6 only relies on renegotiation right before the cutting stage.

\section{References}

Abreu, Dilip, Pearce, David, Stacchetti, Ennio, 1993. Renegotiation and symmetry in repeated games. J. Econ. Theory 60 (2), 217-240.

Alston, Lee J., Andersson, Krister, 2011. Reducing greenhouse gas emissions by forest protection: the transaction costs of implementing REDD. Climate Law 2 (2), 281-289.

Angelsen, Arild, 2010. The 3 REDD 'I's. J. For. Econ. 16 (4), 253-256.

Angelsen, Arild, Kaimowitz, David, 1999. Rethinking the causes of deforestation: lessons from economic models. World Bank Res. Obs. 14 (1), 73-98.

Asheim, Geir, 1991. Extending renegotiation-proofness to infinite horizon games. Games Econ. Behav. 3, $278-294$.

Avenhaus, Rudolf, von Stengel, Bernhard, Shmuel, Zamir, 2002. Inspection games. In: Handbook of Game Theory III: 1947-87. Elsevier, North-Holland, Amsterdam.

Barrett, Scott, 2005. The theory of international environmental agreements. In: Maler, K.-G., Vincent, J.R. (Eds.), Handbook of Environmental Economics, vol. 3.

Battaglini, Marco, Harstad, Bård, 2016. Participation and duration of environmental agreements. J. Polit. Econ. 124 (1), 160-204.

Battaglini, Marco, Salvatore, Nunnaro, Palfrey, Thomas R., forthcoming. The dynamic free rider problem: a laboratory study. Am. Econ. J. Microecon.

Bernheim, B. Douglas, Ray, Debraj, 1989. Collective dynamic consistency in repeated games. Games Econ. Behav. 1, $295-326$.

Binmore, Ken, 1987. Perfect equilibria in bargaining models. In: Binmore, K., Dasgupta, P. (Eds.), The Economics of Bargaining. Basil Blackwell, Oxford.

Björnerstedt, Jonas, Westermark, Andreas, 2009. Stationary equilibria in bargaining with externalities. Games Econ. Behav. 65 (2), 318-338.

Bolton, Patrick, Dewatripont, Mathias, 2005. Contract Theory. MIT Press.

Bulow, Jeremy, 1982. Durable goods monopolists. J. Polit. Econ. 90 (2), 314-332.

Burgess, Robin, Hansen, Matthew, Olken, Ben, Potapov, Peter, Sieber, Stefanie, 2011. The political economy of deforestation in the tropics. Q. J. Econ. 127 (4), 1707-1754. 
Busch, J., et al., 2012. Structuring economic incentives to reduce emissions from deforestation within Indonesia. Proc. Natl. Acad. Sci. 109 (4), 1062-1067.

Chari, V.V., Jones, Larry E., 2000. A reconsideration of the problem of social cost: free riders and monopolists. Econ. Theory 16, 1-22.

Coase, Ronald H., 1972. Durability and monopoly. J. Law Econ. 15, 143-149.

Damette, Olivier, Delacote, Philippe, 2012. On the economic factors of deforestation: what can we learn from quantile analysis? Econ. Model. 29 (6), 2427-2434.

Diamond, Peter A., 1971. A model of price adjustment. J. Econ. Theory 3, 156-168.

Dixit, Avinash, Olson, Mancur, 2000. Does voluntary participation undermine the Coase theorem? J. Public Econ. 76 (3), 309-335.

Duffie, D., Geanakoplos, J., Mas-Colell, A., McLennan, A., 1994. Stationary Markov equilibria. Econometrica 62 (4), $745-781$.

Edenhofer, O. et al., Climate change 2014: mitigation of climate change: contribution of working group III to the fifth assessment report of the intergovernmental panel on climate change, Cambridge, 2014.

Ellingsen, Tore, Paltseva, Elena, 2016. Confining the Coase theorem: contracting, ownership, and free-riding. Rev. Econ. Stud. 83, 547-586.

Engel, Stefanie, Pagiola, Stefano, Wunder, Sven, 2008. Designing payments for environmental services in theory and practice: an overview of the issues. Ecol. Econ. 65 (4), 663-674.

Farrell, Joseph, Maskin, Eric, 1989. Renegotiation in repeated games. Games Econ. Behav. 1 (4), 327-360.

FAO, 2010. State of the World Forests. FAO, Rome.

Framstad, Nils Christian, Harstad, Bård, 2016. Conservation contracts for exhaustible resources. University of Oslo. Mimeo.

Gjertsen, Heidi, Groves, Theodore, Miller, David A., Niesten, Eduard, Squires, Dale, Watson, Joel, 2016. The optimal structure of conservation agreements and monitoring. Mimeo, UCSD.

Gradstein, Mark, 1992. Time dynamics and incomplete information in the private provision of public goods. J. Polit. Econ. 100 (3), 581-597.

Harstad, Bård, 2012. Buy coal! A case for supply-side environmental policy. J. Polit. Econ. 120 (1), 77-115.

Harstad, Bård, Mideksa, Torben, 2016. Conservation contracts and political regimes. University of Oslo. Mimeo.

Hart, Oliver D., Tirole, Jean, 1988. Contract renegotiation and Coasian dynamics. Rev. Econ. Stud. 55 (4), $509-540$.

Hendel, Igal, Lizzeri, Alessandro, 2002. The role of leasing under adverse selection. J. Polit. Econ. 110 (1), $113-143$.

Henderson, J.V., Ioannides, Y.M., 1983. A model of housing tenure choice. Am. Econ. Rev. 73, 98-113.

IPCC, 2007. The fourth assessment report. IPCC, Bonn, Germany.

IPCC, 2013. The fifth assessment report. Cambridge University Press.

Jehiel, Philippe, Moldovanu, Benny, 1995a. Negative externalities may cause delay in negotiation. Econometrica 63 (6), 1321-1335.

Jehiel, Philippe, Moldovanu, Benny, 1995b. Cyclical delay in bargaining with externalities. Rev. Econ. Stud. 62, 619-637.

Jehiel, Philippe, Moldovanu, Benny, 1999. Resale markets and the assignment of property rights. Rev. Econ. Stud. 66 (4), 971-991.

Jehiel, Philippe, Moldovanu, Benny, Stacchetti, Ennio, 1996. How (not) to sell nuclear weapons. Am. Econ. Rev. 86 (4), $814-829$.

Johnson, Justin P., Waldman, Michael, 2010. Leasing, lemons, and moral hazard. J. Law Econ. 53 (2), 307-328.

Katz, Michael L., Shapiro, Carl, 1986. How to license intangible property. Q. J. Econ. 101 (3), 567-589.

Kremer, Michael, Morcom, Charles, 2000. Elephants. Am. Econ. Rev. 90 (1), 212-234.

Lapan, Harvey E., Sandler, Todd, 1988. To bargain or not to bargain: that is the question. Am. Econ. Rev. 78 (2), 16-20.

Levy, Haim, Sarnat, Marshall, 1994. Capital Investment \& Financial Decisions, fifth edition. Prentice Hall Europe, Hertfordshire, Great Britain.

Mailath, George, Postlewaite, Andrew, 1990. Asymmetric information bargaining problems with many agents. Rev. Econ. Stud. 57, 351-367.

Mailath, George J., Samuelson, Larry, 2006. Repeated Games and Reputations. Oxford University Press.

Maskin, Eric, Tirole, Jean, 2001. Markov perfect equilibrium: I. Observable actions. J. Econ. Theory 100 (2), $191-219$.

Muthoo, Abhinay, 1999. Bargaining Theory with Applications. Cambridge University Press, Cambridge, UK.

Osborne, Martin J., 2003. An Introduction to Game Theory. Oxford University Press.

Selten, Reinhard, 1988. A simple game model of kidnappings. In: Selten, R. (Ed.), Models of Strategic Rationality. Kluwer Academic, Boston, pp. 77-93.

Sinn, Hans-Werner, 2008. Public policies against global warming: a supply side approach. Int. Tax Public Finance 15, 360-394. 
Sinn, Hans-Werner, 2012. The Green Paradox. MIT Press.

Somanathan, Eswaran, Prabhakar, Raghavan, Mehta, Bhupendra Singh, 2009. Decentralization for cost-effective conservation. Proc. Natl. Acad. Sci. 106 (11), 4143-4147.

Smith, Clifford W., Wakeman, L. MacDonald, 1985. Determinants of corporate leasing policy. J. Finance 40, 895-908.

Stern, Nicholas, 2008. The economics of climate change. Am. Econ. Rev. Pap. Proc. 98 (2), 1-37.

Tirole, Jean, 1998. The Theory of Industrial Organization, 10th edition. The MIT Press, Cambridge, MA.

Vespa, Emanuel, 2012. Cooperation in dynamic games: an experimental investigation. UCSB. Mimeo. 